STONE CENTER ON SOCIO-ECONOMIC INEQUALITY

WORKING PAPER SERIES

No. 22

Redistribution and Insurance in Welfare States Around the World

Charlotte Bartels

Dirk Neumann

September 2020

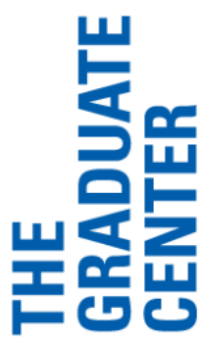

CITY UNIVERSITY 


\title{
Redistribution and Insurance in Welfare States around the World
}

\author{
Charlotte Bartels, Dirk Neumann*
}

September 8, 2020

\begin{abstract}
:
Redistribution across individuals in a one-year-period framework is an empirically intensely studied question. However, a substantial share of annual redistribution might turn out to serve individual insurance in a longer perspective, reducing the level of actual redistribution across individuals. This paper investigates to what extent long-run redistribution diverges from annual redistribution in welfare states of different types. Exploiting panel data from the Cross-National Equivalent File (CNEF) for Australia, Germany, South Korea, Switzerland, the United Kingdom, and the United States, we find that welfare states like Germany that are assumed to engage in a high level of redistribution actually achieve relatively less redistribution between individuals in the long run than the United Kingdom or the United States. Regression results show that a higher share of elderly in a country is associated with more annual redistribution, but with less long-run redistribution between individuals. The results suggest that, in welfare states with aging populations, we might expect growing annual redistribution that, to a substantial extent, is in fact income smoothing for the elderly.
\end{abstract}

JEL Codes: D31, D63, H53, H55, I38

Keywords: Welfare states, redistribution, insurance

\footnotetext{
*Bartels (cbartels@diw.de) is affiliated with DIW Berlin, IZA and UCFS, Neumann (dirk.neumann@bmwi.bund.de) with the German Federal Ministry for Economic Affairs and Energy. Neumann acknowledges support from the European Research Council under the European Union's Seventh Framework Programme (FP7/2007-2013) / ERC grant agreement no. 269831. We thank the editor, Ingvild Almås, and two anonymous referees for helpful comments and suggestions. The paper has also greatly benefited from discussions with Timm Bönke, Giacomo Corneo, Benoit Decerf, Daniel Kemptner, Johannes König, François Maniquet, Nico Pestel, Pierre Pestieau, Panu Poutvaara, and Carsten Schröder as well as seminar and conference participants in Alba-di-Canazei (IT11), Louvain-la-Neuve (CORE), Lund (SSCW 2016), Luxembourg (SIMDECO Workshop, LISER), Mannheim (ZEW Public Finance 2017), NYC (ECINEQ 2017) and Tampere (IIPF 2018). Any errors as well as the views presented in this paper are the responsibility of the authors alone. In particular, the views do not represent the official positions of the German Federal Ministry for Economic Affairs and Energy, or any other organizations with which the authors are affiliated.
} 


\section{Introduction}

Welfare states around the world engage in a high level of income redistribution to reduce income inequality within the population. An extensive body of literature documents the level of annual redistribution in different welfare states. In addition to redistribution, however, welfare states also insure their citizens against sickness, disability, longevity, and unemployment risks, thus stabilizing people's incomes over time. These effects only become evident when extending the measurement period to more than one year. If a welfare state smooths incomes over time, the widely used measures of annual redistribution will overstate redistribution between individuals in the long run, and a substantial share of annual redistribution will turn out to serve in individual income stabilization. For instance, contributions to public pension systems reduce income differences in a society in a given year, but are paid back in retirement, thus stabilizing a person's income stream. ${ }^{1}$ Progressive income taxation not only reduces income differences between individuals, but also compresses individual or household income streams over time.

This paper makes two distinct contributions to the research. First, using panel data from the Cross-National Equivalent File (CNEF) for the years 1970-2013 (in total), we calculate the extent to which the standard measures of annual redistribution widely used in the scientific literature and in public and policy debates overstate the long-run impact of redistribution in six welfare states. CNEF data cover Australia, Germany, South Korea, Switzerland, the United Kingdom, and the United States. In the dataset, pre- and post-government income concepts are harmonized, thus enabling us to compare redistribution across countries. Table 1 gives a ranking of countries by recent annual government expenditures or by the reduction of the Gini coefficient through taxes and transfers, showing that Germany appears to be the most redistributive country of those considered here. Germany's welfare state, classified as corporatist or Bismarckian, is financed largely by social security contributions aimed at maintaining status differences. In contrast, liberal or Beveridgean welfare states like the United Kingdom and the United States are mainly characterized by means-tested benefits providing a minimum level of assistance to low-income groups, independent of the person's labor market status or earnings history (Esping-Andersen; 1990; Bonoli; 1997). We investigate the extent to which a ranking based on annual redistribution, as shown in Table 1 , changes when long-run redistribution is considered. As we are analyzing democratic welfare states, we interpret the derived redistribution measures to be at least partly the result of the demand for (long-run) redistribution within the respective population. Second, based on this assumption, we identify and examine the determinants that are

\footnotetext{
${ }^{1}$ Of course, retirement benefits are not only calculated based on previous pensions contributions, but also contain important redistributive elements, for example by upweighing benefits for periods of low contributions or by granting additional benefits for child raising periods.
} 
able to explain cross-country differences in annual versus long-run redistribution; these include the share of the elderly and migrants, openness of the economy, and societal beliefs about the role of luck.

Table 1: Annual redistribution and welfare state types of CNEF-countries

\begin{tabular}{llcccc}
\hline \hline Rank & Country & $\begin{array}{c}\text { Gov. exp. } \\
\text { in \% of GDP }\end{array}$ & Redistribution & Type I & Type II \\
\hline 1 & Germany & 43.66 & 0.21 & corporatist & Bismarckian \\
2 & United Kingdom & 42.39 & 0.16 & liberal & Beveridgean \\
3 & Australia & 37.81 & 0.15 & liberal & - \\
4 & United States & 37.61 & 0.11 & liberal & Beveridgean \\
5 & Switzerland & 34.03 & 0.09 & liberal & mixed \\
6 & South Korea & 32.30 & 0.04 & productivist & Bismarckian \\
\hline \hline
\end{tabular}

Source: OECD.Stat. Note: Government expenditure for social security purposes in \% of GDP in 2015. Redistribution is measured as the difference between the Gini of market income and the Gini of disposable income in 2014. Type I refers to the welfare state classifications of Esping-Andersen (1990), Kwon and Holliday (2007) introduce "productivist" as a category for East Asian welfare states characterized by the subordination of social policy to economic growth objectives; Type II refers to the welfare state classifications of Bonoli (1997).

Methodically, we assess redistribution by comparing gross (pre-tax, pre-transfer) and net (post-tax, post-transfer) income inequality. To distinguish between annual and long-run redistribution, we first measure total inequality when increasing the length of the period considered, and then decompose this measure into permanent inequality between individuals and individual income variation over time, again before and after government taxes and transfers. Technically, we compute subgroup-decomposable inequality measures over varying period lengths, interpreting realized individual income streams over time as a subgroup. Our measure for (long-run) redistribution between individuals over varying period lengths is the reduction of between-group inequality moving from pre- to post-government household income. For a period of one year in length, the measure collapses into the traditional index of annual redistribution. To compare redistributive performance across countries, we construct a "redistribution ratio": a relative measure that shows the (long-run) redistribution between individuals as a share of overall redistribution. We then investigate potential determinants of annual versus long-run redistribution across the six welfare states using a regression approach.

Our main findings are as follows. First, welfare states like Germany, with more earnings-related benefits and arguably a more status-preserving character turn out to achieve less redistribution between individuals in the long run relative to overall redistribution. Second, ranking countries by their redistributive impact when extending the period beyond one year shows that Anglo-American countries like the United Kingdom and the United States are more redistributive between individuals in a longer perspective than Germany, a corporatist welfare state. We show that differences in long-run 
redistribution across countries are driven by demographic differences (such as household composition and age structure) to only a limited extent, providing support for the argument that welfare state institutions play an important role. Third, regression results show that a higher share of elderly people in the population is associated with more annual but less long-run redistribution between individuals. We discuss various explanations for this finding. One suggestion from the literature is that the elderly vote for annually more redistributive systems, collecting social security contributions and taxes to fund public pensions, which insure the elderly against longevity risk.

The remainder of the paper is structured as follows. Section 2 gives an overview of the literature on this topic. Section 3 introduces our conceptual framework and methodology for measuring long-run redistribution, based on the Theil coefficient and the Mean Logarithmic Deviation. Section 4 describes the data. Section 5 presents our results for long-run redistribution across countries. In Section 6, we examine potential explanatory variables for cross-country differences using a regression approach. Section 7 concludes.

\section{Literature review}

Our paper relates to various strands of the literature. As noted in the introduction, while annual redistribution is still the predominant concept considered when assessing how government policies reduce income inequalities, there is also a substantial and growing literature that analyzes income redistribution over the lifecycle (Nelissen; 1995, 1998; Björklund and Palme; 2002; Pettersson and Pettersson; 2007; Ter Rele; 2007; Bovenberg et al.; 2008; Hoynes and Luttmer; 2011; Bartels; 2012; Bengtsson et al.; 2016; Levell et al.; 2017; Haan et al.; 2018; Roantree and Shaw; 2018).

Some of these studies explicitly consider the stabilizing or income-smoothing component of government redistribution, usually referred to as insurance. In this literature, both components, i.e., annual redistribution and insurance, are usually calculated as differences between pre- and post-government income (inequalities). ${ }^{2}$ Bartels (2012), Haan et al. (2018), and Björklund and Palme (2002) decompose the Theil coefficient. Both Bartels (2012) and Haan et al. (2018), using data from the German Socio-Economic Panel (SOEP), find that the German welfare state offers more insurance than redistribution. Furthermore, Haan et al. (2018) find that taxes and

\footnotetext{
${ }^{2}$ This approach is also found in the literature decomposing individual earnings dynamics into a permanent component, which reflects the disparity of permanent incomes, and a transitory component, which covers short-term income volatility. The traditional approach employed in studies on earnings dynamics decomposes the total variance structure, following the seminal contribution of Gottschalk and Moffitt (1994). See, e.g., Dynarski and Gruber (1997), Haider (2001), Baker and Solon (2003), Dynan and Sichel (2012), Beach and Gray (2010), Shin and Solon (2011), Moffitt and Gottschalk (2012), Cappellari and Jenkins (2014). In this literature, the reduction of earnings shocks through the tax-benefit system is interpreted as insurance (Blundell et al.; 2015).
} 
unemployment insurance in Germany are much more effective at redistributing lifetime income than insuring lifetime earnings risk, whereas disability benefits are not redistributive. Social assistance turns out to be the most important transfer program for both insurance and redistribution. Roantree and Shaw (2018), using data from the British Household Panel Survey (BHPS), find that the share of insurance in total redistribution increases as the period length increases. Bovenberg et al. (2008), using administrative data from Denmark, find that $74 \%$ of total redistribution serves to reduce income differences between individuals over the lifetime, while $26 \%$ serves income smoothing.

However, research on long-run redistribution in a cross-country perspective, contrasting different types of welfare states, is scarce as the data requirement is large: Income smoothing can empirically only be separated from redistribution if comparable longitudinal data on pre- and post-government income streams can be observed over long time spans. Examples also using CNEF data are Chen (2009) comparing Canada, Germany, the United Kingdom, and the United States as well as Bartels and Bönke (2013) comparing Germany and the United Kingdom. This paper attempts to fill this gap by extending the analysis to six welfare states covered in CNEF and, for the first time, also investigating explanatory factors for observed cross-country differences.

In interpreting our results, we connect to the literature on preferences for, and the political economy of, redistribution by exploring different channels through which the explanatory factors for cross-country differences in redistribution in our analysis might work. Here, we comment on the most widely discussed channels in the literature, which also play an important role with regard to the explanatory variables in Section 6 of our paper. These are pre-tax inequality, share of elderly, openness of the economy, migration, and the role of luck. ${ }^{3}$

On the one hand, the canonical model of Meltzer and Richard (1981) implies that redistribution increases with pre-government income inequality. Milanovic (2000) and Scervini (2012) provide empirical evidence of this relationship. Buchanan (1976) shows that income uncertainty leads taxpayers to support redistribution due to the element of insurance it entails. On the other hand, the prospect of upward mobility (POUM) might weaken support for redistributive schemes among today's poor, while sufficiently risk-averse individuals might support redistribution because of social insurance (Benabou and Ok; 2001; Ravallion and Lokshin; 2000).

Razin et al. (2002) identify a redistribution trade-off in aging societies: As the number of retirees increases, the demand for benefits increases, but the willingness of the working-age population to support redistribution falls, as they are net losers from the increased benefits to the elderly. Analyzing data from the United States and 12 European countries, they find a negative association between the share of retirees in the

\footnotetext{
${ }^{3}$ See Alesina and Giuliano (2001) for an overview.
} 
population and the size of the welfare state: namely, the tax rate on labor income and the generosity of social transfers. They argue that the decisive voter is of working age in most western countries and hypothesize that continued aging of societies, leading to a retired median voter, might very well flip the result. Tabellini (2000) and Moene and Wallerstein (2001) find empirical evidence of a positive association between the share of the elderly and government spending on social insurance. All of the above studies focus on annual redistribution. Our approach enables us to disentangle redistribution (between individuals) and insurance (over an individual's life-cycle) and to investigate potentially different directions of the elderly population's impact on annual and longrun redistribution.

Rodrik (1998) finds a positive correlation between government spending and trade openness, hypothesizing that societies demand (and receive) an expanded role of government and more social insurance and/or benefits at the price of accepting larger doses of external risk.

Soroka et al. (2006) argue that migration reduces solidarity within a community and thereby reduces support for redistribution. Empirically, migration (Dahlberg et al.; 2012) and racial heterogeneity (Luttmer; 2001) are found to reduce the demand for redistribution.

Studies on preferences for redistribution generally stress the importance of societal beliefs: If people believe that the unequal distribution of incomes is due to luck, they are less willing to accept high inequality levels and are more likely to support redistribution (Alesina and Angeletos; 2005; Fong; 2001; Corneo and Grüner; 2002).

Finally, we discuss some of the results of our paper in light of the paradox of redistribution (PoR) formulated by Korpi and Palme (1998). The authors argue that welfare states providing universal benefits are more redistributive than welfare states providing targeted, means-tested benefits. Policies aimed at maintaining the living standards of the entire population will be widely supported by the population, which in turn increases the size of the budget available for redistribution and is likely to result in greater redistribution. Moene and Wallerstein (2001), analyzing inequality of disposable income using LIS data, find that income distributions in universal welfare states are more equal than in welfare states with basic security and targeted support schemes, especially in Australia, Switzerland, and the United States. Casamatta et al. (2000) show that it may be appropriate to engage in less redistribution than otherwise optimal but to maintain adequate coverage of social insurance in order to ensure political support. We contribute to the discussion of the PoR by quantifying the share of individual insurance in overall redistribution across welfare states. 


\section{Conceptual framework}

Our goal is to measure the long-run redistributive impact of welfare states. In particular, we seek to examine how long-run income differences between individuals ( $\mathrm{in}_{\text {- }}$ ter-individual inequality) and individual income variation over time (intra-individual inequality) are reduced by the tax-transfer system and how this reduction varies across countries. The former is what we refer to as "redistribution between individuals" in this paper; the latter we call, in line with the literature, "insurance". We split individual $i$ 's equivalized household income $y$ in year $t$ over period length $p$ into two components:

$$
y_{i, t, p}=\bar{y}_{i, p}+\nu_{i, t, p}
$$

where $\bar{y}_{i, p}$ denotes the individual's average income over period length $p . \nu_{i, t, p}$ is the transitory component, reflecting the annual deviation from the individual's permanent income path. Ideally, the term $\nu_{i, t, p}$ would capture purely exogenous shocks. However, in practice, self-insuring behavioral reactions to income shocks, such as increased working hours or increased savings, potentially mitigate the effect of a shock in both the short and the long run. We do not explicitly account for these behavioral reactions; rather we take them as given, as we aim to capture the redistributive and stabilizing impact of the welfare state on realized income streams on top of what households might have mitigated themselves beforehand. ${ }^{4}$ Furthermore, most of the literature shows that behavioral responses to income shocks are quite small because most workers hold fixed work contracts. ${ }^{5}$

Total income inequality $I^{\text {total }}$ over period length $p$ is decomposed into permanent income inequality and individual income variation over time. $p$ denotes the period length and ranges from 1, where our approach collapses to the traditional annual approach, to 13 years (see also Section 4). The between-group component, $I^{\text {between }}$, measures income differences between people (inter-individual inequality) and the within-group component, $I^{\text {within }}$, measures individual income variation over time (intra-individual inequality), while each individual income stream is interpreted as a subgroup. We compute inequality measures for different starting years in order to capture the relevant shifts over time:

$$
I^{\text {total }}\left(y_{i, t, p}\right)=I^{\text {between }}\left(\bar{y}_{i, p}\right)+I^{\text {within }}\left(\nu_{i, t, p}\right) .
$$

\footnotetext{
${ }^{4}$ For instance, Hoynes and Luttmer (2011) and Haan et al. (2018) take an ex ante perspective and estimate individual-level income trajectories, which enables them to identify elements of government policies that act as insurance against unexpected shocks, which in turn requires strong assumptions on the structure of earnings trajectories, as this requires a functional form to be chosen to model individual income paths. Haan et al. (2018) restrict their analysis to earnings, as simulating family income would require further assumptions on household formation and fertility decisions.

${ }^{5}$ Heathcote et al. (2014) find that $15.5 \%$ of wage fluctuations are smoothed through individual labor supply. Zang (2014) finds that labor supply responses to a spouse's adverse wage shocks reduce earnings instability by about 2 to $9 \%$.
} 
The standard time frame for inequality measurement is $p=1$. If $p=1$, then $I^{\text {within }}=0$ and $I^{\text {total }}=I^{\text {between }}$. The greater $p$, the lower is $I^{\text {between }}$ and the greater is $I^{\text {within }}$. That is, by extending the measurement period, individual income variation over time explains an increasing portion of total inequality.

We measure and decompose total inequality $I^{\text {total }}$ employing the Theil coefficient, denoted $T^{\text {total }}{ }^{6}$ Björklund and Palme (2002), Bartels (2012), and Haan et al. (2018) use the Theil coefficient in the same context. As a robustness check, we also employ the Mean Logarithmic Deviation (MLD), denoted $M^{\text {total }}$. The decomposition of the Theil coefficient over period length $p$ is represented as follows:

$$
T^{\text {total }}=\underbrace{\frac{1}{N} \sum_{i=1}^{N} \frac{\bar{y}_{i, p}}{\bar{y}_{p}} \ln \frac{\bar{y}_{i, p}}{\bar{y}_{p}}}_{\text {between }}+\underbrace{\frac{1}{N} \sum_{i=1}^{N} \frac{\bar{y}_{i, p}}{\bar{y}_{p}} T_{i}}_{\text {within }} .
$$

$\bar{y}_{p}$ is the population average income over period length $p . T_{i}=\frac{1}{p} \sum_{t=1}^{p} \frac{y_{i, t, p}}{\bar{y}_{i, p}} \ln \frac{y_{i, t, p}}{\bar{y}_{i, p}}$ is the Theil index of individual $i$.

The total MLD is defined as:

$$
M^{\text {total }}=\underbrace{\frac{1}{N} \sum_{i=1}^{N} \ln \frac{\bar{y}_{p}}{\bar{y}_{i, p}}}_{\text {between }}+\underbrace{\frac{1}{N} \sum_{i=1}^{N} M_{i, p}}_{\text {within }},
$$

where $M_{i}=\frac{1}{p} \sum_{t=1}^{p} \ln \frac{\bar{y}_{i, p}}{y_{i, t, p}}$ is the MLD of individual $i$.

As regularly done in the literature, we measure redistribution $R$ as the absolute difference between pre- and post-government income inequality, $I(y)$ and $I(x)$, respectively, with equivalized pre-government household income denoted $y$ and equivalized post-government household income denoted $x .{ }^{7}$ We compute the redistribution index for period length $p$ and starting year $t$ as

$$
R_{t, p}=I\left(y_{i, t, p}\right)-I\left(x_{i, t, p}\right) .
$$

Given that we base $R_{t, p}$ on subgroup decomposable inequality measures, $R_{t, p}$ can be computed for total inequality as well as for between- and within-group inequality. If $R_{t, p}^{\text {between }}>R_{t, p+1}^{\text {between }}$, then redistribution between individuals decreases with period

\footnotetext{
${ }^{6}$ The maximum value that the Theil coefficient can take is $\log$ of $n$, meaning that the Theil coefficient is not independent of the number of observations. Thus, we might expect that our country rankings are influenced by the different population sizes of the countries investigated. However, the country redistribution rankings we derive in Section 5 are robust against scaling up or down the population size in a specific country. For example, increasing the population in Switzerland even by a factor of ten while keeping the population of the other countries of comparison fixed leaves our results unchanged.

${ }^{7}$ If there is no re-ranking between the pre- and post-government income distribution, then this measure collapses to the Reynolds-Smolensky index (Reynolds and Smolensky; 1977).
} 
length $p$, which indicates that we would overestimate the redistributive impact of the welfare state if we applied a traditional annual measurement framework in each year of period $p$. The reduction of the between-group component is our measure of interest.

To explicitly capture the decline of the redistributive effect when extending the measurement period, we define a redistribution ratio $R R_{t, p}$, which is the share of redistribution between individuals in overall redistribution:

$$
R R_{t, p}=\frac{I^{\text {between }}\left(\bar{y}_{i, t, p}\right)-I^{\text {between }}\left(\bar{x}_{i, t, p}\right)}{I\left(y_{i, t, p}\right)-I\left(x_{i, t, p}\right)} .
$$

$R R_{t, p}=1$, if inequality is traditionally measured on a cross-section, i.e., $p=1$, while $R R_{t, p}<1$ if $p$ increases. The higher (lower) $R R_{t, p}$ is when $p$ increases (for a given $t$ ), the more we would conclude that a government favors (sacrifices) redistribution between individuals - relative to "insurance", as defined above - in the long run. Conceptually, this approach is similar to Shorrocks' $R$ (Shorrocks; 1978) measuring the ratio of permanent to total inequality.

We conclude this section with a remark on the relative notion of $R R_{t, p}$. Note that a high $R R_{t, p}$ does not necessarily imply high (low) levels of redistribution (insurance). Rather, the impact of levels is intentionally canceled out in our redistribution ratio. Take, for instance, two countries $a$ and $b$, with the same levels of initial inequalities, $I\left(y_{i, t, p}\right)$ and $I^{\text {between }}\left(\bar{y}_{i, t, p}\right)$, of which $a$ proves to be strongly redistributive overall (in terms of a large denominator in $R R_{t, p}$ ) while $b$ does not. Both may end up with an identical $R R_{t, p}$ : namely, if they reduce inequality between individuals by the same proportion relative to overall inequality. ${ }^{8}$ In order to compare the relative weight of redistribution versus insurance across countries, this is what matters most to our view and what is meant when we state that "a country $a$ appears to be relatively more (or less) redistributive in the long run than a country $b$ ". This does not suggest that different levels of redistribution between countries are not of interest, but it is not the focus of our paper.

\section{Data}

We use panel data from the Cross-National Equivalent File (CNEF) 1970-2013 for Australia (AU), Germany (DE), South Korea (KR), Switzerland (CH), the United Kingdom (UK), and the United States (US). CNEF contains equivalently defined variables, most importantly pre- and post-government income, from the following representative household panel surveys: the Household Income and Labour Dynamics in Australia

\footnotetext{
${ }^{8}$ Consider the following simplified example of two redistribution ratios (denoted $R R_{\text {country }}$ ) for the overall highly redistributive country $a$ and the overall less redistributive country $b: R R_{a}=\frac{0.2-0.05}{0.4-0.1}=$ 0.5 and $R R_{b}=\frac{0.2-0.15}{0.4-0.3}=0.5$. Although country $a$ also redistributes more between individuals than country $b$ when considering levels, we would still conclude that both countries are equally redistributive in terms of the redistribution ratio.
} 
(HILDA), the German Socio-Economic Panel (SOEP), the Korea Labor and Income Panel Study (KLIPS), the Swiss Household Panel (SHP), the British Household Panel Study (BHPS), and the Panel Study of Income Dynamics (PSID) for the United States. ${ }^{9}$ In addition to producing their original panel data files, all panel study teams produce a CNEF data file in which variable names and concepts are harmonized for purposes of cross-country comparison. Pre-government household income is commonly defined as the sum of household labor earnings, household asset income, household private transfers, and household private retirement income. Post-government household income is commonly defined as pre-government household income plus household public transfers minus household social security pensions and total household taxes. Burkhauser et al. (2001) discuss the construction of comparable variables and supply a list of supporting publications. Most of the panel studies only started in the 1990s, such that data are available only for a subset of years between 1970-2013 for most countries, as outlined in Table 2.

\begin{tabular}{lllc}
\multicolumn{4}{c}{ Table 2: CNEF-panel data availability by country } \\
\hline \hline Country & Code & Survey & Period \\
\hline Australia & AU & HILDA & $2001-2013$ \\
Germany & DE & SOEP & $1984-2013$ \\
South Korea & KR & KLIPS & $2003-2008$ \\
Switzerland & CH & SHP & $1999-2013$ \\
United Kingdom & UK & BHPS & $1992-2006$ \\
United States & US & PSID & $1970-2009$ \\
\hline \hline
\end{tabular}

Our income measure is annual pre- and post-government household income equivalized using the modified OECD scale. ${ }^{10}$ We take an ex post perspective and use income streams realized in the past as they are documented in our panel data. Our period length is between 1 and 13 years, because a maximum period length of 13 years is available for four of our six countries (when starting in year 2001, see Section 5), namely Australia, Germany, Switzerland, and the United States, although CNEF data for Germany and the United States would allow an even longer maximum period length starting in 1984 and 1970, respectively. Whereas incomes are converted to 2010 US dollar purchasing power parities (USD PPP) to adjust for inflation and purchasing power differences between countries, we do not discount incomes. ${ }^{11}$

\footnotetext{
${ }^{9}$ Unfortunately, the Russian panel study RLMS-HSE, which is also included in CNEF, does not include pre-government income and, therefore, cannot be included in our analysis.

${ }^{10}$ For South Korea, we recomputed pre- and post-government household income according to CNEF definitions, as the definitions in the original data do not meet the CNEF standard. For instance, public transfers and social security pensions were included in pre-government household income. Additionally, we top-coded income taxes to a maximum of $20 \%$ of pre-government household income for all countries as some of the imputed income taxes seemed unreasonably high, sometimes even exceeding pre-government household income. We chose $20 \%$ as the maximum rate because income taxes do not exceed $20 \%$ of pre-government income for $99 \%$ of the sample.

${ }^{11}$ When taking an ex ante perspective in predicting future income streams, one would discount
} 
Table 3 lists the income components of pre- and post-government income in the CNEF. Consumption taxes and in-kind benefits are not documented in the data and, thus, not included. It is well known that consumption taxes are often less redistributive, if not regressive. ${ }^{12}$ Verbist and Matsaganis (2014) suggest that the redistributive impact of in-kind benefits is as large as that of monetary benefits and note that their relative importance in social spending appears to be increasing in European countries.

Table 3: From pre- to post-government income in the CNEF

\begin{aligned} \hline \hline Income component & Included \\ \hline Pre-government income & Labor earnings, asset income, private transfers and pensions \\ - Social security contributions & Contributions to pension insurance, health-care insurance, \\ & unemployment insurance \\ - Income taxes & All direct taxes on pre-government income \\ + Social security pensions & Payments from old age, disability, widowhood pension schemes \\ + Public transfers & Unemployment benefits, social assistance, housing allowances, \\ & child and maternity benefits, government student assistance, etc. \end{aligned}

Since we are interested in the empirically prevalent mix of redistribution and income smoothing for the population as a whole in the different welfare states, we compute all inequality and redistribution measures based on the income distribution of the entire population and refrain from distinguishing specific cohorts or age groups for our baseline results. ${ }^{13}$ However, we study alternative sample specifications and also consider the impact of socio-demographic differences by employing a reweighting procedure. Reform effects are smoothed out to a certain extent in our framework of extended period length. Moreover, we provide results for different starting years to check the robustness of the patterns observed in each country over time. Finally, we control for differences in countries' demographic composition and include time dummies when explaining differences in the observed redistribution patterns in our regression approach in Section 6.

future income streams to a Net Present Value (NPV). We refrain from discounting incomes for three reasons. First, we do not take an ex ante but an ex post perspective, using income streams observed in the past. Second, discounting incomes compresses observed individual income streams and, thereby, reduces intra-individual inequality relative to inter-individual inequality. Consequently, discounted incomes would produce less insurance but unchanged redistribution. Third, the choice of the discount rate strongly influences time trends of intra-individual inequality. Taking market interest rates introduces additional variability to both pre- and post-government income streams, which would make our results less straightforward to interpret. Nevertheless, results with discounted incomes using market interest rates or a constant discount factor of $3 \%$ are available from the authors upon request.

${ }^{12} \mathrm{CNEF}$ data do not provide information on consumption and saving. Focusing on income streams rather than consumption streams, we neglect the stabilizing effect of private saving and dissaving. Changes in private saving behavior as a response to changes in welfare states' provision of insurance are of central importance for the optimal design of taxes and benefits that should maximize social welfare but minimize disincentives and crowding-out effects. However, taking this into account is beyond the scope of this paper.

${ }^{13}$ Additionally, we are restricted by the rather small sample size of individuals observed continuously over 13 years. 


\section{Redistribution in the long run}

Welfare states that aim at redistributing income, not only on an annual basis but also in the long run, are likely to direct some of their policies toward canceling out permanent income differences between individuals. Typical means to achieve long-run redistribution are progressive income taxation and means-tested benefits, but also to some extent social insurance schemes that contain redistributive elements (see also footnote 1). In this respect, the reduction of the between-group component of income inequality - to which we refer as long-run redistribution - is our measure of interest. Accordingly, the reduction of the within-component captures income smoothing by the government, e.g., through progressive income taxation, old-age pensions, as well as unemployment, disability, and sickness benefits. Our focus in this and the next section is on the former, i.e., the long-run redistributive impact of welfare states and how this differs from annual redistribution in a cross-country comparative context. By focusing on this, we are also able to derive conclusions about the relative importance of insurance.

We start by first showing how inter- and intra-individual (pre-government) inequality evolve when extending the time period of interest beyond one year. In a second step, we repeat this exercise for post-government inequality, which enables us to provide initial insights into the extent of the government's reduction of both types of inequality. In a third step, we compute our redistribution ratio for the different countries. Finally, before turning to the regression exercise in the subsequent section, we deepen the analysis and calculate the redistributive impact for alternative specifications of interest.

Inter- and intra-individual inequality in the long run. Figure 1 shows how the composition of total pre-government income inequality changes when extending the traditional annual measurement framework to a multiple-year framework. Income differences between individuals decline in size when extending the period length, whereas the importance of individual income variation increases. For each country, total inequality of pre-government income is shown in the left-hand panel, inter-individual inequality in the middle panel, and intra-individual inequality in the right-hand panel. Each marker represents a separately computed Theil index for the respective period length, $p$, and a given starting year, $t$. For instance, starting in the year 2001, the Theil for a period length of $1(2, \ldots, 13)$ is thus the Theil in year 2001 (over years 2001-02, .., 2001-13). To check the robustness of our results over time, Theil indices are displayed for different selected starting years, $t$.

As Figure 1 shows, total inequality is about 0.4 in Australia, Germany, Switzerland, and the United States, and about 0.3 in South Korea, and the United Kingdom. The decomposition shows that the majority of total income inequality is explained by income differences between individuals (inter-individual inequality). However, individ- 
ual income variation over time (intra-individual inequality) increases total inequality by a non-negligible percentage. The longer the period, the more important individual income variation becomes in explaining overall income differences. By construction, the intra-individual component equals zero if the period length is 1 . Individual income variation reaches about 0.1 in most of the countries when considering a period length of 10 years. In sum, the decline of inter-individual inequality when extending the period length is approximately compensated for by the increase of intra-individual inequality, such that total inequality remains relatively stable with respect to period length. This pattern is consistent overall across the different starting years selected. Decomposing inequality measured by the MLD shows a similar pattern (see Appendix, Figure A.2).

Figure 1: Theil decomposition by period length, for different starting years
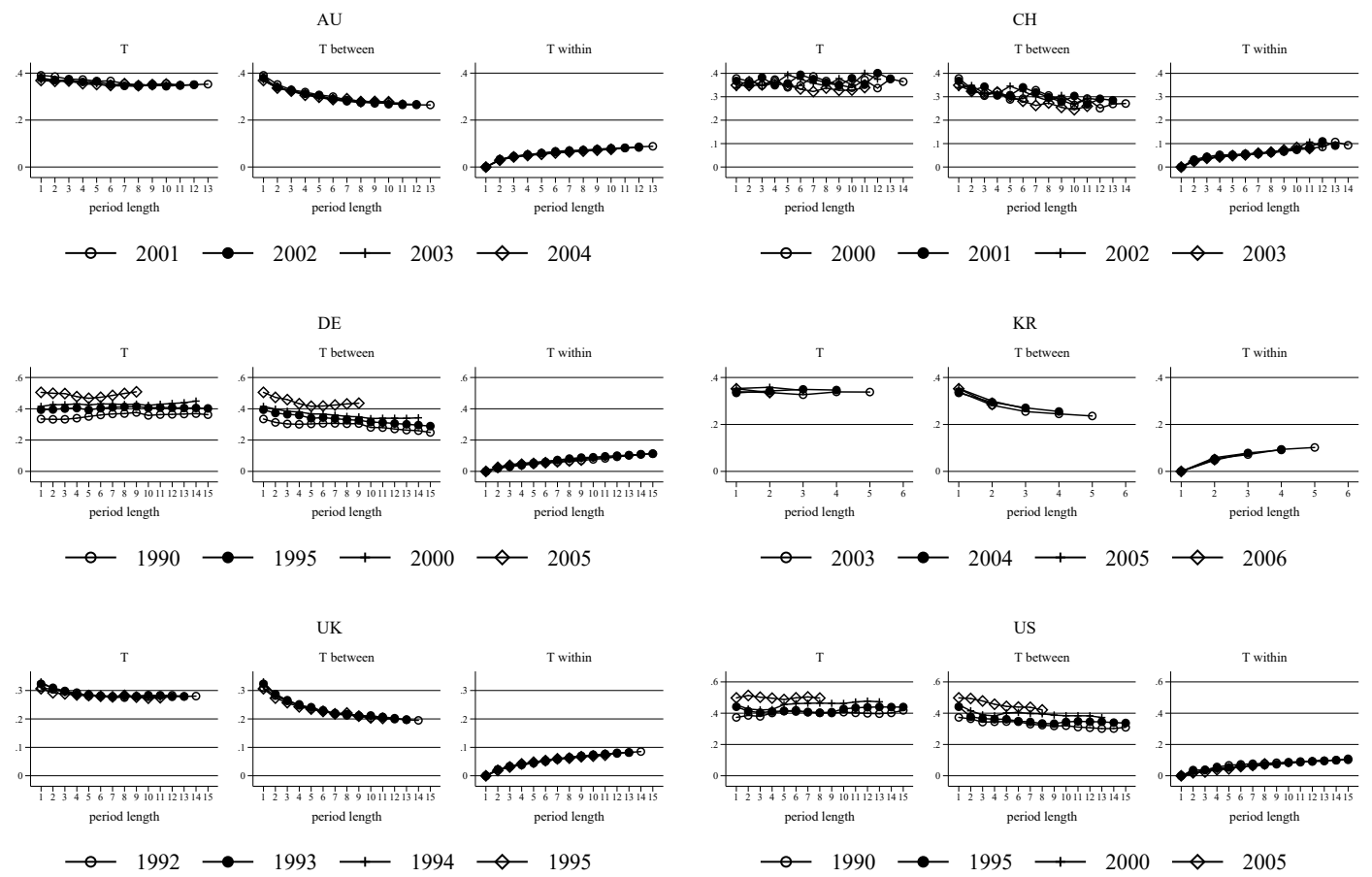

Source: Cross-National Equivalent File (CNEF). Note: Theil indices are calculated based on pre-government equivalized household income in 2010 USD PPP for a maximum period length of 15 years. We use at least some starting years around the millennium for all countries except the United Kingdom, where panel data including post-government incomes are only available up to 2006, such that the earliest starting year for a 14-year period length is 1992 .

Government reduction of inter- and intra-individual inequality. Whereas Figure 1 compares the between- and within-group components of pre-government inequality, we now turn to the question to what extent welfare states reduce income inequality. We therefore also compute post-government inequality components and calculate the difference between the respective components before and after taxes and transfers. The extent of redistribution using the traditional annual approach might change when we extend the measurement period to take individual income variation and the stabilization thereof by the welfare state into account. Figure 2 shows the 
redistribution index for inter-individual and intra-individual inequality reduction for varying period lengths and different starting years between 2001 and 2005, which are covered by all the countries in the CNEF data. As a result, from the different time spans available, the number of plots by country and their respective period length varies across countries. For instance, KLIPS data from South Korea only cover 2003 to 2008, resulting in relatively short period lengths and few plots, whereas German SOEP data cover the period 1984 to 2016. Moreover, data on the United Kingdom from the BHPS stop in 2008, meaning that the starting years 2001 to 2005 used in Figure 2 only allow relatively short period lengths to be displayed for this country.

We first comment on the redistributive effect measured by government reduction of the between-group inequality component, shown in the left-hand panel of Figure 2. In an annual perspective, i.e., taking a period length equal to one, Germany clearly ranks first, followed by Australia, Switzerland, and the United Kingdom, the United States, and South Korea. However, redistribution between individuals becomes less pronounced when extending the period length, which changes the ranking of the countries, as long-run redistribution turns out to be of differing importance across each of the different welfare states. In a longer perspective, the United Kingdom is less redistributive than the United States, while Australia is less redistributive than Switzerland. All in all, long-run inequality between individuals is reduced by about 0.3 Theil index points in Germany, 0.2 in Australia, by 0.1 to 0.2 in Switzerland, the United Kingdom and the United States, and by only 0.04 points in South Korea. The reduction of within-group inequality captures income smoothing by the welfare state, shown in the right-hand panel of Figure 2. In contrast to redistribution between individuals, the reduction of individual income variation increases quite steadily with period length, while the extent of income smoothing by the welfare state is much smaller than redistribution (0.02 to 0.07 as opposed to 0.1 to 0.3 index points) in absolute terms. Again, Germany ranks first and South Korea last. Computing the MLD instead of the Theil coefficient ranks Switzerland as both the most redistributive and most stabilizing country, as seen in the Appendix, Figure A.3, whereas Germany ranks second. Apart from these two countries switching ranks, the picture remains the same. 
Figure 2: Government reduction of the Theil between and within component by period length
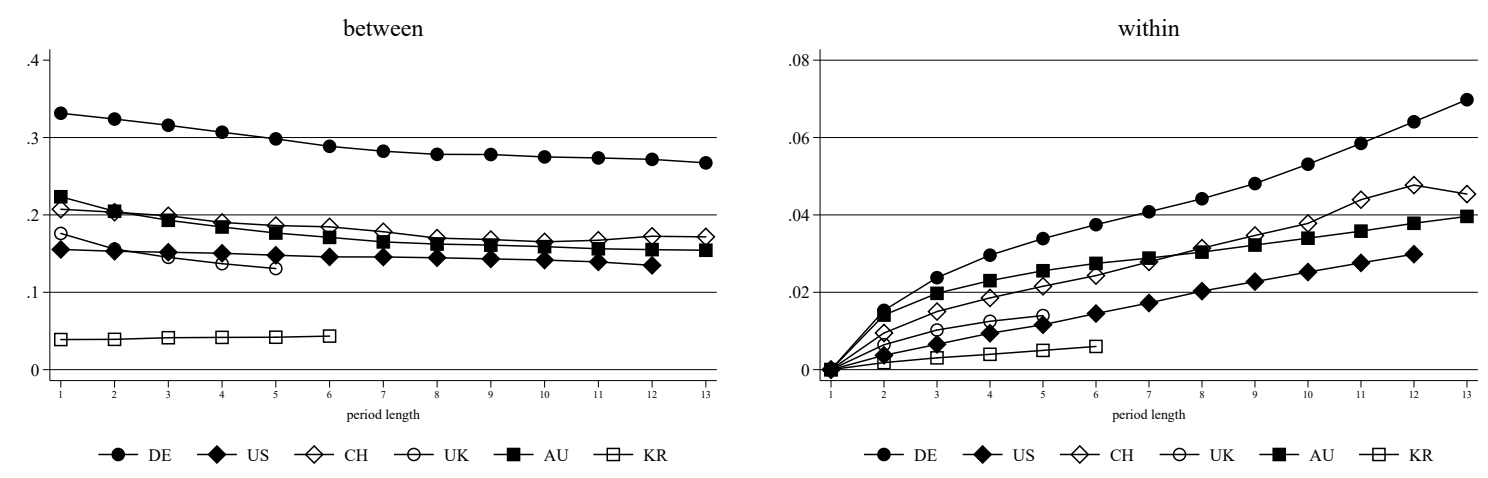

Source: Cross-National Equivalent File (CNEF). Note: Inequality is measured by the Theil coefficient. Inequality reduction is measured by the redistribution index $R=I(Y)-I(X)$, where $Y$ is equivalized pre-government household income and $X$ is equivalized post-government household income in 2010 USD PPP. Average values over starting years 2001 to 2005.

Redistribution ratio. As mentioned, we are particularly interested in the relative importance of long-run redistribution between individuals across countries, as opposed to annual redistribution. In order to further investigate this question, we present our redistribution ratio, defined in Section 3 as the share of inter-individual inequality reduction in total inequality reduction, in Figure 3. As shown in Figure 2, the German welfare state redistributes to a large extent between individuals, but at the same time stabilizes incomes to a large extent over time. Figure 3 shows how much of overall inequality reduction over a given period length serves to reduce long-run income differences between individuals. Two noteworthy patterns emerge.

First, the redistribution ratio considerably decreases when extending the period length beyond one year. For a four-year period length, 90\%, if not less, of overall inequality reduction serves long-run redistribution. For a 13-year period length, the redistribution declines to roughly $80 \%$. This finding is in line with Roantree and Shaw (2018), who find for the United Kingdom that after 14 years, inter-personal redistribution amounts to only $90 \%$ of total redistribution. Bovenberg et al. (2008) find that the redistribution ratio is $74 \%$ in Denmark over a lifetime. Second, the US government's interventions seem to be proportionately more redistributive between individuals than in all other welfare states considered, irrespective of the period length. In contrast, Germany and Australia, which appeared to be highly redistributive from an annual perspective (see the left-hand panel of Figure 2 for $p=1$ ), provide less redistribution between citizens in the long run. This indicates support for the paradox of redistribution (Korpi and Palme; 1998) mentioned in Section 2: The population may support the redistribution of resources in an annual context, as these welfare states also offer comparably high insurance. Additionally, by comparison, South Korea seems to devote more resources to income smoothing than to redistribution. Both findings hold when computing the MLD instead of the Theil coefficient (see Appendix, Figure A.4). 
Figure 3: Theil, redistribution ratio by period length

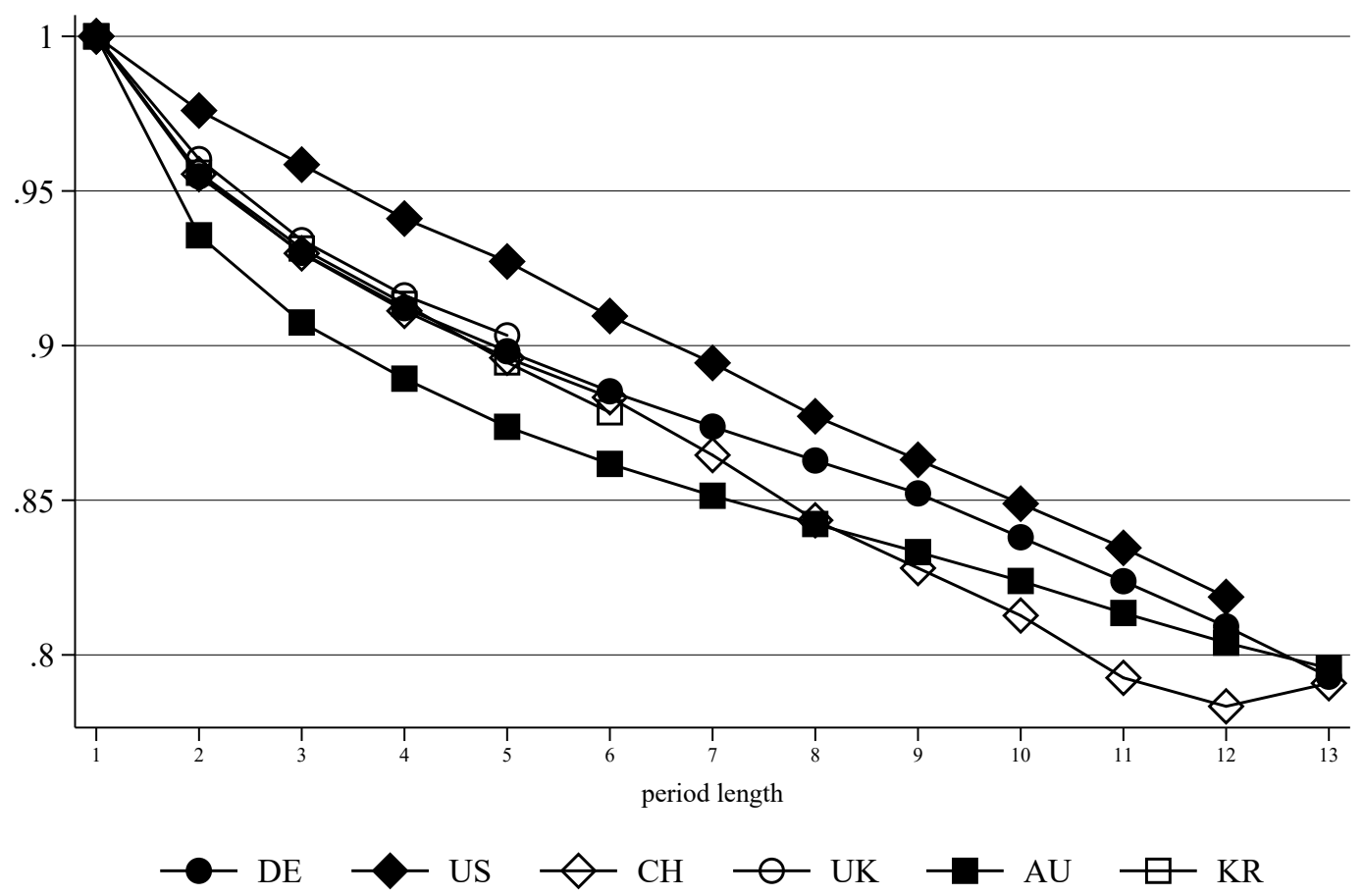

Source: Cross-National Equivalent File (CNEF). Note: Inequality is measured by the Theil coefficient. The redistribution ratio $R R$ is defined as $\left[I^{\text {between }}(Y)-I^{\text {between }}(X)\right] /[I(Y)-I(X)]$, where $Y$ is equivalized pre-government household income and $X$ is equivalized post-government household income in 2010 USD PPP. Average values over starting years 2001 to 2005. Year-specific plots (for starting years covering a maximum period length of 15 years) are shown in the Appendix in Figure A.1 for the Theil and in Figure A.4 for the MLD.

Adjusted country rankings. Table 1 in the Introduction illustrates how countries can be ranked in terms of their annual redistributive performance, using annual government expenditure for social security purposes or the reduction of the Gini coefficient through taxes and transfers. Table 4 reproduces a similar ranking when using reductions of the Theil coefficient as reported in Figure 2 (i.e., for a period length of one year). Again, Germany turns out to be the most redistributive country on an annual basis, followed by the Anglo-American countries and Switzerland, respectively, as well as, finally, South Korea. However, this ranking substantially changes when extending the measurement period. For instance, when considering a five year period, the United States turn out to be the most redistributive country in relative terms (based on our redistribution ratio as reported in Figure 3), followed by the United Kingdom in second, and Germany in third. The United States keep this position also when considering ten years.

The impact of age and household structure. To quantify the importance of cross-country differences in the demographic structure of populations as well as household composition for our redistribution ratio, we employ the reweighting method established by DiNardo-Fortin-Lemieux (DFL) (DiNardo et al.; 1996). The goal is to 
Table 4: Country rankings for annual and long-run redistribution

\begin{tabular}{lcccccc}
\hline \hline Rank & \multicolumn{2}{c}{ Annual- } & \multicolumn{3}{c}{ Long-run-Redistrib. } \\
& \multicolumn{2}{c}{$R_{1}$} & \multicolumn{2}{c}{$R R_{5}$} & \multicolumn{2}{c}{$R R_{10}$} \\
\hline 1 & DE & 0.33 & US & 0.93 & US & 0.85 \\
2 & AU & 0.22 & UK & 0.90 & DE & 0.84 \\
3 & CH & 0.21 & DE & 0.89 & AU & 0.82 \\
4 & UK & 0.18 & CH & 0.89 & CH & 0.81 \\
5 & US & 0.16 & KR & 0.89 & & \\
6 & KR & 0.04 & AU & 0.87 & & \\
\hline \hline
\end{tabular}

Note: Ranking of countries according to results presented in Figures 2 and 3 based on average values over starting years 2001 to 2005 .

assess the extent to which long-run redistribution differences between countries can be explained by differences in the country-specific household type and age distributions. For example, Bönke et al. (2020) use the DFL method to investigate the role of household and age distributions for wealth inequality differences between Germany and the United States. In the following, we explain how we adapt the DFL method to our purposes.

Let each household be characterized by a vector $(y, z, c)$ comprising a continuous variable $y$ (pre- or post-government income), a vector of attributes $z$ (i.e., age and household structure), and a country identifier $c$. The joint distribution of income and attributes in a country is $F(y, z, c)$, while $F(y, z \mid c)$ denotes the distribution of $y$ conditional on the distribution of $z$ in $c$. Following DiNardo et al. (1996), the density of income in a given country $c, f_{c}(y)$, can be written as

$$
f_{c}(y) \equiv f\left(y ; c_{y}=c, c_{z}=c\right) .
$$

The notation allows us to express the density of $y$ in a given country conditional on the distribution of attributes $z$ in another country. For example, while $f\left(y ; c_{y}=\mathrm{DE}, c_{z}=\mathrm{DE}\right)$ denotes the actual density of income in Germany (DE), $f\left(y ; c_{y}=\mathrm{DE}, c_{z}=\mathrm{US}\right)$ is the counterfactual density of income in Germany, applying the distribution of attributes in the United States (US). The aim of the DFL reweighting method is to estimate the counterfactual density, which (taking the example for DE and US) is defined as

$$
\begin{aligned}
f\left(y ; c_{y}=\mathrm{DE}, c_{z}=\mathrm{US}\right) & =\int f\left(y \mid z, c_{y}=\mathrm{DE}\right) d F\left(z \mid c_{z}=\mathrm{US}\right) \\
& =\int f\left(y \mid z, c_{y}=\mathrm{DE}\right) \phi_{z}(z) d F\left(z \mid c_{z}=\mathrm{DE}\right),
\end{aligned}
$$


where $\phi_{z}(z)$ denotes the reweighting function

$$
\phi_{z}(z)=\frac{d F\left(z \mid c_{z}=\mathrm{US}\right)}{d F\left(z \mid c_{z}=\mathrm{DE}\right)}=\frac{\operatorname{Pr}(c=\mathrm{US} \mid z)}{\operatorname{Pr}(c=\mathrm{DE} \mid z)} \cdot \frac{\operatorname{Pr}(c=\mathrm{DE})}{\operatorname{Pr}(c=\mathrm{US})} .
$$

The probability of being a resident of country $c$, given individual attributes $z$, can be estimated with a probit model:

$$
\operatorname{Pr}\left(c_{z}=c \mid z\right)=\operatorname{Pr}\left(\epsilon>-\beta^{\prime} H(z)\right)=1-\phi\left(-\beta^{\prime} H(z)\right) .
$$

where $\phi(\cdot)$ is the cumulative normal distribution and $H(z)$ is a vector of covariates.

We split the total population into 20 subcategories with four age groups $(<30$ years, 30-49 years, 50-64 years, and 65 years and older) and five household types (single, lone parent, couple without/with children, and other households). We construct two counterfactuals. First, populations of all countries are reweighted for each available year according to the distribution of attributes in the United States in 2001 (including the US itself for all other years except 2001). Second, we repeat the reweighting procedure using the population of Germany in 2001 as a baseline. We chose Germany and the United States as baseline countries given their large population sizes but relatively different socio-demographic structures and welfare state typologies. Germany's population is relatively old (see elderly share in Table 5 in Section 6) and the welfare state is of the corporatist/Bismarckian type, while the US population is relatively young and the welfare state is of the liberal/Beveridgean type. We choose 2001 as the base year as the redistribution ratios above are based on the starting years 2001 to 2005.

Figure 4 presents the results of our DFL reweighting exercise. The panel on the top right-hand side shows redistribution ratios applying the United States' age-household structure in 2001. The bottom right-hand panel shows redistribution ratios applying the German age-household structure in 2001. Both panels are compared to the baseline redistribution ratios shown in Figure 3 and repeated in the left-hand panels. Two findings are noteworthy. First, Australia's redistribution ratio moves upwards relative to the other countries, such that, broadly speaking, reweighted redistribution ratios become more similar across countries (at least when applying the US age-household structure in 2001). This means that some of the cross-country variation is indeed explained by socio-demographics, particularly for Australia, with its comparably young population. Second, however, the United States remain an outlier with a markedly higher redistribution ratio. This finding holds when applying either the US or the German age-household structure in 2001, thus indicating that differences in sociodemographics do not account for much of the elevated US redistribution ratio. We conclude that differences in the long-run redistribution across countries are only driven to a limited extent by socio-demographic differences (such as household composition or age structure), providing support for the importance of welfare state institutions. 
Figure 4: Theil, reweighted redistribution ratio
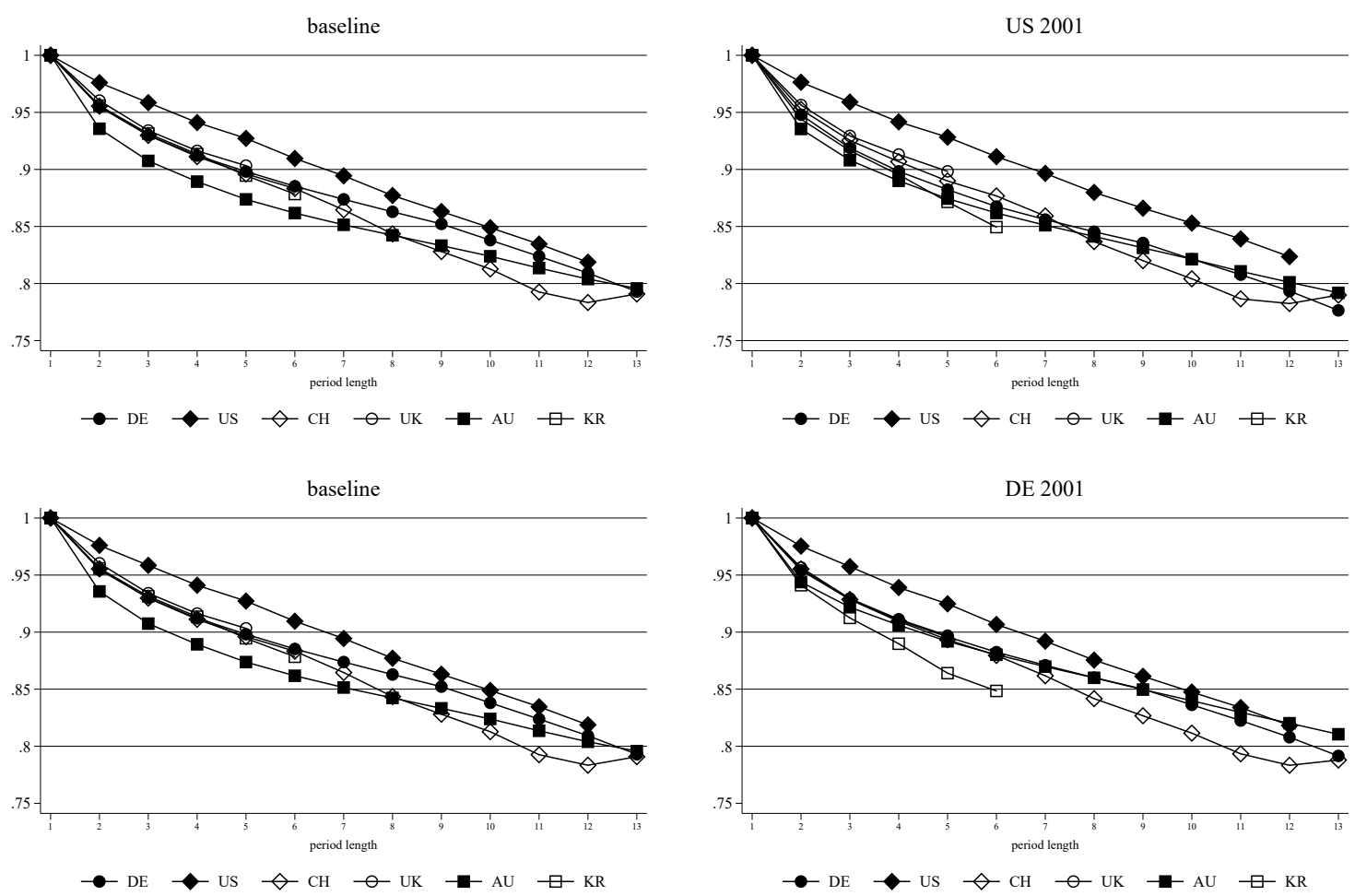

Source: Cross-National Equivalent File (CNEF). Note: Inequality is measured by the Theil coefficient. The redistribution ratio $R R$ is defined as $\left[I^{\text {between }}(Y)-I^{\text {between }}(X)\right] /[I(Y)-I(X)]$, where $Y$ is equivalized pre-government household income and $X$ is equivalized post-government household income in 2010 USD PPP. Average values over starting years 2001 to 2005.

The impact of the elderly and public pensions. In many welfare states, the elderly make up a growing share of the population, and public pensions are often the largest spending item in government budgets. As argued above, the impact of the elderly on the redistributive character of welfare states is complex and, in some cases, ambiguous. It is therefore important to assess the extent to which the pattern observed in Figure 3 is driven by the share of the elderly in the population, or by the share of social security pensions. This is done in Figure 5, which reproduces Figure 3 when cancelling out the impact of the elderly and public pensions on the redistributive character of welfare states to some extent. The top right-hand panel shows the redistribution ratio based on a sample restricted to the working-age population between 25 and 65 years. The bottom right-hand panel counts social security pensions as pre-government income, i.e., interpreting pensions as deferred income. Unfortunately, Australia does not provide information on public pensions as a separate variable in the CNEF data, which means that we cannot add public pensions to gross household income for Australia and cannot show results for Australia in the bottom right-hand panel.

Compared to the baseline redistribution ratio repeated in the left-hand panels, both panels show that the pattern of the redistribution ratio across countries shown in Figure 3 is broadly confirmed. In the top right-hand panel, the United States, with 
its relatively young population, turns out to be more redistributive, whereas Germany with a relatively old population turns out to be less redistributive by comparison. This can be expected, as a higher share of transfers and benefits (other than pensions) will serve as insurance over the life cycle in older populations. The bottom right-hand panel counts social security pensions as pre-government income, overall confirming the pattern shown in Figure 3. This means that even without taking into account the income-smoothing function of public pensions, most of the six welfare states under analysis appear to be relatively less redistributive in the long run. South Korea's redistribution ratio even exceeds one when counting social security pensions as market income (not shown in the bottom right-hand panel). ${ }^{14}$

Figure 5: Theil, redistribution ratio excl. elderly and public pensions
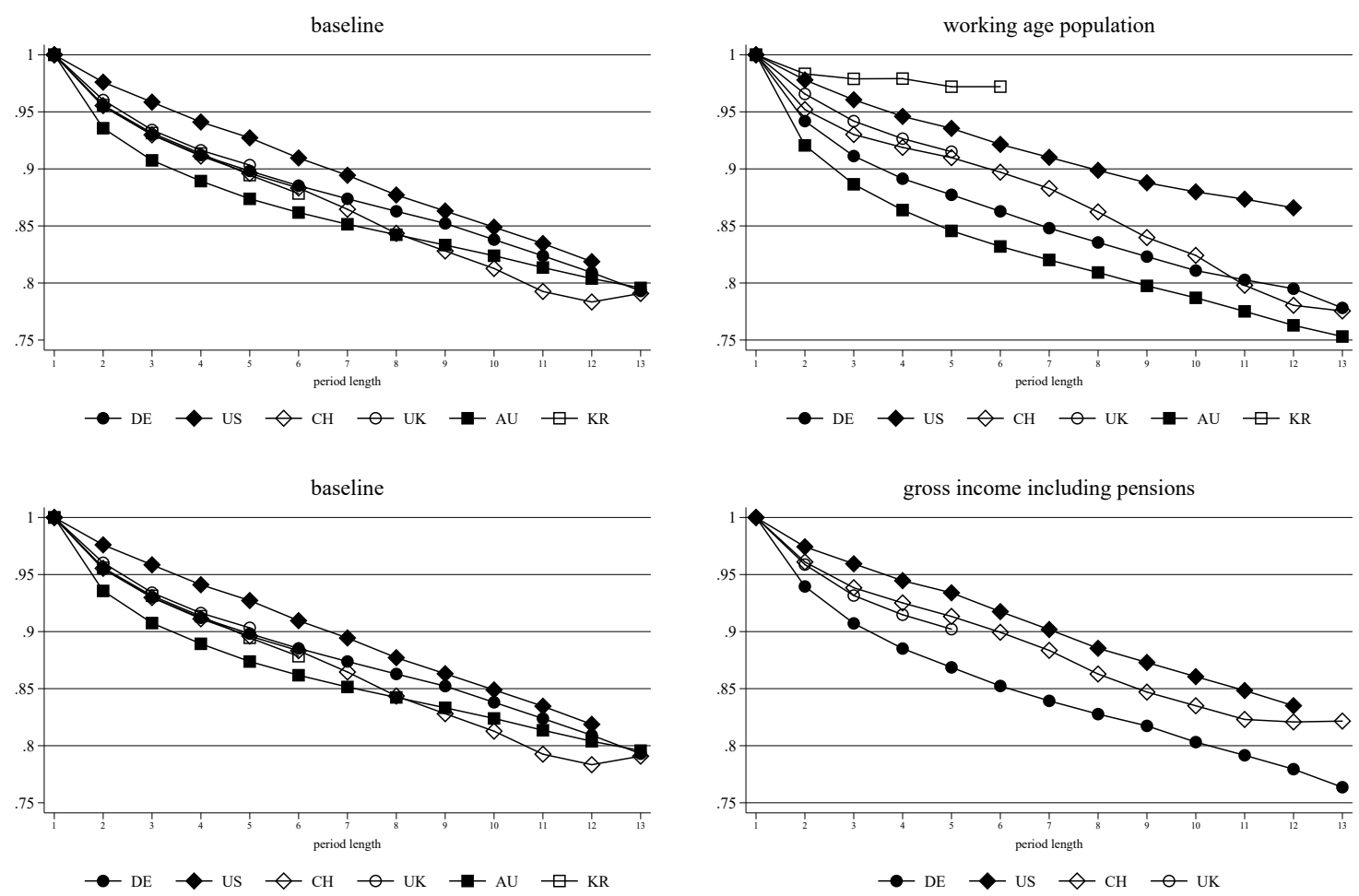

Source: Cross-National Equivalent File (CNEF). Note: Inequality is measured by the Theil coefficient. The redistribution ratio $R R$ is defined as $\left[I^{\text {between }}(Y)-I^{\text {between }}(X)\right] /[I(Y)-I(X)]$, where $Y$ is equivalized pre-government household income and $X$ is equivalized post-government household income in 2010 USD PPP. Average values over starting years 2001 to 2005. No information on public pensions is available for Australia.

Intergenerational redistribution. While in the previous exercise, public pensions did not turn out to predominantly impact differences in the redistribution ratio across countries, they might still play an important role in how welfare state types differ in redistributing between different generations by means of their public pension

\footnotetext{
${ }^{14}$ This results from the fact that social security pensions in South Korea are much more incomesmoothing than income taxes and public transfers, whereas basic means-tested assistance for the elderly only amounts to about $6 \%$ of average earnings (OECD; 2017). Consequently, within-group inequality is higher for post-government income than for pre-government income, including social security pensions. Hence, the denominator of Eq. 6 is smaller than the numerator, and the redistribution ratio exceeds one. As this result is only induced by the construction of this exercise - which is provided for purposes of illustration - South Korea is excluded from the figure.
} 
system. More precisely, in this subsection, we investigate to what extent long-run income differences between two groups - pension recipients and non-recipients, who are probably still paying social security contributions to the pension system - are mitigated by the government. In order to analyze this question, we have to further decompose the between-group inequality component. That is, we only consider long-run income inequality between individuals and define the income streams of pensioners and nonpensioners as further subgroups. Hence, when decomposing the between-group inequality component, the reduction of between-group inequality now measures redistribution between individuals across the groups of pensioners and non-pensioners, whereas the reduction of the within-component measures redistribution between individuals within both groups. We classify individuals as public pension recipients if they are members of a household in which a public pension has been received for at least one year within a given period length.

To evaluate the resulting pattern, we make use of the welfare state classification presented in Table 1 in the Introduction, now applied to the public pension system only. Accordingly, retirement schemes can be classified into Bismarckian systems, where earnings-related pensions are mainly financed by earnings-related contributions, and Beveridgean systems, characterized by tax-financed, flat-rate benefits providing an old-age income adequate to ensure a minimum standard of living (Jensen et al.; 2004). Germany, South Korea, Switzerland, and the United States follow the Bismarckian tradition, whereas Australia and the United Kingdom are known for their Beveridgean pension systems. As mentioned, Australia does not provide information on public pensions in the CNEF data, meaning that we must exclude it from this exercise as well. On the one hand, we expect that Beveridgean systems are more redistributive from an intergenerational perspective (i.e., between pensioners and non-pensioners), given that pension schemes are less earnings-dependent in these welfare states and, thus, more equalizing (Jensen et al.; 2004). On the other hand, Bismarckian systems, which we would expect to be less intergenerationally redistributive given their more pronounced dependence on individual earnings, often provide generous means-tested minimum pensions and top-cap pensions for high-income earners, so they might eventually turn out to be highly intergenerationally redistributive as well.

The left-hand panel of Figure 6 is equivalent to the left-hand panel of Figure 2 and shows the reduction of long-run income differences between the two socio-demographic groups of pensioners and non-pensioners (we only show the reduction of the betweengroup component as we are interested in intergenerational redistribution). Germany reduces intergenerational inequality by 0.1 , Switzerland by 0.08 , and the United Kingdom and United States by about 0.02 index points. Germany and Switzerland therefore engage in more intergenerational redistribution between the groups of pensioners and non-pensioners than the other countries. While pensions in both countries depend 
on previous earnings, they also provide generous means-tested pensions (or equivalent basic subsidies for the elderly) that amount to about $20 \%$ of average earnings (OECD; 2017). The United States and the United Kingdom show quite similarly sized intergenerational inequality reductions. The lowest level of intergenerational redistribution occurs in South Korea (see also footnote 14). ${ }^{15}$ This pattern remains roughly unchanged when extending the period length over which long-run income is measured.

To complete the picture presented in this exercise, we construct an intergenerational redistribution ratio shown in the right-hand panel of Figure 6. This ratio is different from the redistribution ratio in Figure 3, since now it captures the share of populationwide long-run redistribution (which is largely directed from non-pensioners to pensioners). The right-hand panel of Figure 6 confirms that Germany and Switzerland also show the highest level of intergenerational redistribution between non-pensioners and pensioners in relative terms, with no significant difference across the different period lengths considered.

In sum, neither the absolute (in terms of the difference between pre- and postgovernment inequality) nor the relative (in terms of the redistribution ratio) reduction of intergenerational inequality between individuals is clearly higher for a specific welfare state type when considering public pension systems. At best, we might conclude that Bismarckian types with generous basic subsidies to the elderly tend to redistribute more in relative terms between generations, given that Germany's welfare state is of the Bismarckian type and Switzerland exhibits both Bismarckian and Beveridgean features.

Figure 6: Theil, intergenerational redistribution
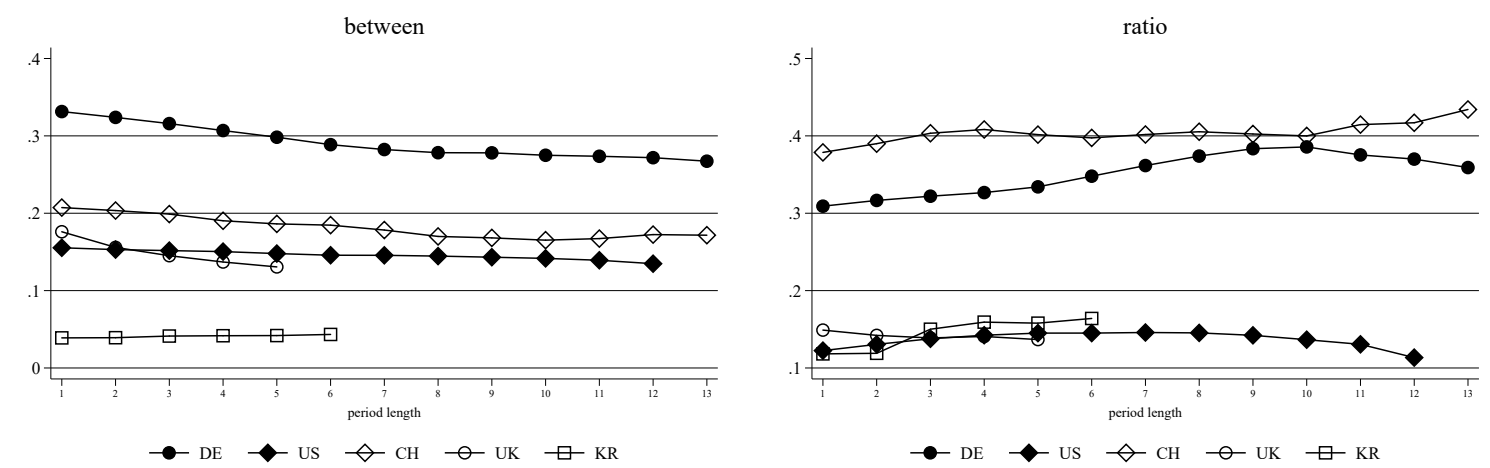

Source: Cross-National Equivalent File (CNEF). Note: Inequality is measured by the Theil coefficient. The redistribution ratio $R R$ is defined as $\left[I^{\text {between }}(Y)-I^{\text {between }}(X)\right] /[I(Y)-I(X)]$, where $Y$ is equivalized pre-government household income and $X$ is equivalized post-government household income in 2010 USD PPP. Average values over starting years 2001 to 2005. No information on public pensions is available for Australia.

\footnotetext{
${ }^{15}$ Our findings might change if we could assess individual Net Present Values (NPV) of future pensions payments. We could then credit payments against contributions, thus assessing how much individuals gain or lose over the life cycle. However, this would require a microsimulation model that is harmonized for all CNEF countries, which, unfortunately, is not available.
} 


\section{$6 \quad$ Explaining cross-country differences}

In the previous section, we analyzed to what extent long-run redistribution between individuals differs from annual redistribution across countries. In this section, we investigate potential explanatory factors for the observed cross-country variation in annual and long-run redistribution. Given that we are analyzing democratic welfare states, we interpret our estimated redistribution measures to be - at least partly the result of the demand for redistribution and insurance within a population. Take the effect of the share of elderly people, for example: Individuals in aging societies might vote for higher taxes and social security contributions during working life in anticipation of later retiring and enjoying higher benefits as a retiree. Similarly, we expect retirees to vote in favor of higher taxes and social security contributions in order to increase the retirement benefits they are currently receiving (which may comprise increased contribution-based pensions as well as additional means-tested benefits).

We address the role of explanatory factors by estimating the following basic regression equation:

$$
\Re_{c t p}=X_{c t}^{\prime} \beta+\alpha_{c}+\mu_{t}+\epsilon_{c t p}
$$

where $\Re_{c t p}$ is a measure for redistribution in country $c$ with starting year $t$ over period length $p$. Hence, $\Re_{c t 1}$ measures traditional annual redistribution in year $t . X_{c t}$ is a vector of explanatory variables that are often used in the literature explaining crosscountry differences in inequality and redistribution. These are inequality of market income, the elderly share, openness of the economy, migration, and the role of luck. As $X_{c t}$ indicates, we regress on explanatory factors as measured in year $t$. When considering long-run redistribution, year $t$ is taken as the starting year of the period considered. By doing so, we assume that the observed long-run redistribution is - at least partly - the result of the explanatory variables' role in the demand for (shortand long-run) redistribution expressed in year $t$.

Market income inequality and the share of the elderly (defined as the population above age 60) are derived from the CNEF data. Openness of the economy is measured as the export share in GDP, which is taken from the Penn World Tables 9.0. Migration per capita is available at the website OECD.Stat. The role of luck is the average result from the World Value Survey question asking respondents to choose a value between 1 and 10 according to their own belief that either Hard work usually brings a better life (1) or It is more a matter of luck and connections (10), which is also used in Alesina and Angeletos (2005). $\alpha_{c}$ is a country fixed effect, $\mu_{t}$ captures year effects (or rather period effects), and $\epsilon_{c t p}$ is the error term. When assessing annual redistribution, we take the redistribution index defined in Eq. 5 as our measure for redistribution $\Re_{c t 1}$, and estimate Eq. 11 using OLS. To assess long-run redistribution in the next step, we 
take the redistribution ratio defined in Eq. 6 as the dependent variable and estimate Eq. 11 for varying period lengths using GLS. In order to address serial correlation in the error term $\epsilon_{c t p}$ when increasing the period length to more than one year, we directly allow for an AR process of an order equal to the period length $p$.

Average values of the explanatory variables by country are given in Table 5 . On average, market income inequality is lower in the United Kingdom and Switzerland but higher in Germany and Australia. Germany and the United Kingdom show the highest share of the elderly in the population, with $40 \%$ of the population older than 60. In contrast, this share is only $22 \%$ in South Korea and $28 \%$ in Australia and the United States. The economies of Switzerland, Germany, and South Korea are the most open as measured by the share of exports in GDP. Switzerland had the largest inflow of migrants per capita during the period under investigation. The belief that luck determines income is more prevalent in Switzerland and Germany, whereas the belief that hard work brings success is more prevalent in the United States. Table 5 also lists the expected impact of the explanatory variables on annual and long-run redistribution: "+" for a positive, "-" for a negative, and "?" for an ex ante unclear impact. We further comment on this below when presenting the estimation results.

Table 5: Descriptive statistics and expected impact of explanatory variables

\begin{tabular}{lccccc}
\hline \hline Country & Pre-gov. Gini & Elderly share & Openness & Migration p.c. & Luck \\
\hline AU & 0.511 & 0.278 & 0.227 & 0.008 & 4.207 \\
CH & 0.475 & 0.325 & 0.576 & 0.014 & 5.254 \\
DE & 0.534 & 0.392 & 0.365 & 0.009 & 5.362 \\
KR & 0.473 & 0.220 & 0.343 & 0.009 & 4.061 \\
UK & 0.462 & 0.392 & 0.237 & 0.003 & 4.550 \\
US & 0.489 & 0.279 & 0.076 & 0.003 & 3.636 \\
Dependent var. & & Expected impact of explanatory variables & \\
Annual red. & + & + & + & - & + \\
Long-run red. & $?$ & - & - & - & n.a. \\
\hline \hline
\end{tabular}

Note: Averages by country across CNEF data years (see Table 2.) Pre-government Gini and elderly share (population above age 60) are own calculations from CNEF data. Exports in \% of GDP are from Penn World Tables 9.0. Migration per capita is from OECD.Stat. The role of luck is from the World Value Survey.

Explaining annual redistribution. Regression results estimated via OLS using the traditional annual redistribution measure $R_{1}$, the redistribution index, as dependent variable, are presented in Table 6. Explanatory variables are added sequentially in columns (1) to (5). We start with the two explanatory factors that are most discussed in the literature - pre-government income inequality and the share of the elderly - then sequentially add further explanatory variables ordered by the number of country-year observations. We expect higher market income inequality to be associated with significantly higher annual redistribution, as the relatively poor median voter in countries 
with high market income inequality is likely to be in favor of redistribution (Meltzer and Richard; 1981). This is indeed what we find, ${ }^{16}$ which is in line with results from previous studies, e.g., Milanovic (2000), who also finds higher redistribution in countries with greater market income inequality. As for the interpretation of results, column (1), for instance, states that a one-point increase in pre-government Gini increases annual redistribution (measured as the difference between pre- and post-government Theil) by 1.215 index points.

As suggested in the previous section, the share of the elderly might play a particularly important role in explaining annual versus long-run redistribution. However, the theoretical and empirical literature on the effect of the elderly share on redistribution is ambiguous. Razin et al. (2002) identify a trade-off due to aging: The greater number of retirees increases the demand for benefits but reduces the willingness of the working-age population to support redistribution, as they are net losers from increased benefits for the elderly. However, we find that a higher share of the elderly is associated with significantly more annual redistribution. This is in line with the positive associations also found by Tabellini (2000) and Moene and Wallerstein (2001). However, both studies aim to capture the insurance rather than the redistributive effect, using annual expenditures for social security and insurance programs as the dependent variable to explain differences across welfare states. We will come back to this point of contention when discussing the regression results for long-run redistribution. Indeed, annual redistribution in a country with a high share of the elderly might very well turn out to be income-smoothing over a longer period.

For the openness of the economy, we expect a positive association with annual redistribution. This assumption builds on Rodrik (1998), who reports a positive correlation between government spending and trade openness, hypothesizing that societies demand (and receive) an expanded role of the government and more social insurance and/or benefits at the price of larger doses of external risk. In our regressions, openness of the economy shows a positive association with annual redistribution, which, however, is insignificant in most specifications.

Soroka et al. (2006) argue that migration reduces solidarity within a community and, thereby, reduces support for interpersonal redistribution, which might hold in the short- as well as in the long-run. In our regressions, migration indeed shows a negative association with redistribution, but as for openness of the economy, effects are insignificant in most specifications.

Finally, the belief that luck determines income (rather than hard work) is associated with significantly more annual redistribution, which is in line with Alesina and Angeletos (2005), who argue that the social desirability of redistribution increases with the share of income that is due to luck (as opposed to effort).

\footnotetext{
${ }^{16}$ The only exception is column (5), which shows an insignificant effect. However, one should note that regression (5) is based on a limited number of observations induced by the luck variable.
} 
The inclusion of country fixed effects absorbs most of the cross-country variation, as seen by the large increase in the adjusted R-squared between columns (1) and (2). This means that most of the differences in annual redistribution across countries are due to country-specific features that remain constant over time, such as welfare state types. In our long-run redistribution regressions, we include interaction effects to further investigate the role of welfare state types. Qualitatively, regressions based on the MLD show the same results overall, except for the effect of luck, which turns insignificant (see Appendix, Table A.1). The coefficients are larger because the MLD is larger, on average, than the Theil coefficient.

Table 6: Explaining annual redistribution

\begin{tabular}{lccccc}
\hline \hline \multicolumn{5}{c}{ Dependent variable: annual redistribution $R_{1}$ based on Theil } \\
& $(1)$ & $(2)$ & $(3)$ & $(4)$ & $(5)$ \\
\hline Pre-gov.gini & $1.215^{* * *}$ & $0.802^{* * *}$ & $0.390^{* * *}$ & $0.386^{* *}$ & 0.379 \\
& $(0.128)$ & $(0.176)$ & $(0.141)$ & $(0.189)$ & $(0.248)$ \\
Elderly share & & & $0.670^{* * *}$ & $0.581^{* * *}$ & $0.971^{* * *}$ \\
& & & $(0.090)$ & $(0.097)$ & $(0.123)$ \\
Exports \% of GDP & & & & $0.080^{* *}$ & 0.122 \\
& & & & $(0.034)$ & $(0.110)$ \\
Migrants p.c. & & & & -0.789 & -1.858 \\
& & & & $(1.266)$ & $(1.170)$ \\
Luck & & & & & $0.032^{*}$ \\
& No & Yes & Yes & Yes & $(0.017)$ \\
\hline Country/year effects & 0.469 & 0.915 & 0.961 & 0.963 & 0.986 \\
Adj. $R^{2}$ & 119 & 119 & 119 & 114 & 45 \\
N & & & & & \\
\hline \hline
\end{tabular}

Note: Regressions are based on data for all CNEF countries listed in Table 5. Standard errors are heteroscedasticity-robust and indicated in brackets. $* * *=$ significant at the 1 percent level, $* *=$ significant at the 5 percent level, ${ }^{*}=$ significant at the 10 percent level. Pre-government Gini and elderly share (population above age 60 ) are own calculations from CNEF data. Exports in \% of GDP are from Penn World Tables 9.0. Migration per capita is from OECD.Stat. The role of luck is from the World Value Survey 1994, 2005, 2010. Fewer observations in (4) and (5) are due to fewer country-year observations for the respective explanatory variables.

Explaining long-run redistribution. We now turn to regression results explaining long-run redistribution, where the redistribution ratio, $R R_{p}$, across varying period lengths, $p$, is our dependent variable. Unfortunately, we only have one or a maximum of three (Germany) observations per country for the role of luck and therefore cannot include this variable in our long-run regressions. GLS regression results for varying period lengths using both Theil and MLD are shown in Table $7 .{ }^{17}$ As for the interpretation of results in this case, we would conclude in the first column, for instance, that a one-point increase in pre-government Gini reduces long-run redistribution (as

\footnotetext{
${ }^{17}$ We refrain from displaying a stepwise introduction of explanatory variables because this alters neither sign nor significance of the estimated coefficients. The estimation for period lengths of more than six years is not feasible due to limited data availability across countries.
} 
measured by the redistribution ratio) by 0.199 points.

The association between market income inequality and long-run redistribution is ex ante less clear than for annual redistribution. In principle, one could expect a negative as well as positive effect depending on whether (the reduction of) inter- or intra-personal inequality turns out to be more important on average across countries. In Table 7, the effect is negative and significant for most period lengths, while it is significantly positive only for $p=3$ using the Theil. This suggests that higher market income inequality tends to be associated with more income smoothing and less long-run redistribution.

As mentioned above, the sign of the coefficient for the share of the elderly in the population might very well change when considering long-run redistribution rather than annual redistribution, i.e., the sign might turn negative. Reformulating the trade-off identified by Razin et al. (2002), we hypothesize that a greater number of retirees increases the demand for insurance, i.e., income smoothing rather than long-run redistribution. Our findings are in line with this rationale, as the coefficient is negative and highly significant using the long-run redistribution ratio for various period lengths. ${ }^{18}$ This result is robust to an alternative setting, where we restrict our sample to the working-age population (see Appendix, Table A.2). The negative association between long-run redistribution and the share of the elderly - which implies a positive association between income smoothing and elderly share - is supported by, e.g., Tabellini (2000) and Moene and Wallerstein (2001), who find a positive association between government spending for insurance and the share of elderly. However, in order to more neatly connect to studies like Razin et al. (2002), which explicitly address the intraversus intergenerational effects of redistribution and the political support for redistribution, we would need to analyze detailed panel data on income and redistributive preferences or voting across countries, which, unfortunately, is beyond the scope of this paper.

Trade openness largely shows a negative association with long-run redistribution. This supports the "insurance" argument of Rodrik (1998) mentioned above, according to which people demand more income smoothing when facing higher external risk.

Migration is associated with significantly less long-run redistribution in most specifications. This provides evidence for Soroka et al. (2006), cited above. The result is also in line with Sandmo (2002), who argues that the threat of emigration of top taxpayers in high-tax countries may induce these welfare states to provide relatively more insurance.

${ }^{18}$ The only exception of a small positive effect arises for $p=4$ using the Theil. 
Table 7: Explaining long-run redistribution

\begin{tabular}{lcccccccc}
\hline \hline & \multicolumn{9}{c}{ Dependent variable: redistribution ratio $R R_{p}$ based on } \\
& \multicolumn{7}{c}{ Theil } & \multicolumn{7}{c}{ MLD } \\
& $R R_{2}$ & $R R_{3}$ & $R R_{4}$ & $R R_{5}$ & $R R_{2}$ & $R R_{3}$ & $R R_{4}$ & $R R_{5}$ \\
\hline Pre-gov.gini & $-0.199^{* * *}$ & $0.186^{* *}$ & -0.090 & 0.043 & $-0.713^{* *}$ & $-0.609^{* * *}$ & $-0.719^{* * *}$ & 0.042 \\
& $(0.069)$ & $(0.094)$ & $(0.070)$ & $(0.050)$ & $(0.323)$ & $(0.192)$ & $(0.210)$ & $(0.122)$ \\
Elderly share & $-0.099^{* * *}$ & $-0.322^{* * *}$ & $0.070^{*}$ & $-0.074^{*}$ & $-0.621^{* * *}$ & $-0.684^{* * *}$ & -0.134 & $-0.585^{* * *}$ \\
& $(0.025)$ & $(0.035)$ & $(0.041)$ & $(0.041)$ & $(0.124)$ & $(0.148)$ & $(0.233)$ & $(0.114)$ \\
Exports \% of GDP & -0.031 & 0.026 & $-0.062^{* *}$ & $-0.049^{* *}$ & 0.048 & 0.050 & -0.036 & $0.063^{*}$ \\
& $(0.021)$ & $(0.018)$ & $(0.025)$ & $(0.020)$ & $(0.046)$ & $(0.042)$ & $(0.073)$ & $(0.034)$ \\
Migrants p.c. & -0.879 & $-0.542^{* *}$ & $0.878^{* *}$ & $-1.166^{* * *}$ & -3.120 & $-3.168^{* *}$ & -0.677 & -0.013 \\
& $(0.633)$ & $(0.232)$ & $(0.344)$ & $(0.408)$ & $(2.614)$ & $(1.458)$ & $(1.104)$ & $(0.809)$ \\
\hline Country/year effects & Yes & Yes & Yes & Yes & Yes & Yes & Yes & Yes \\
$\mathrm{N}$ & 108 & 99 & 94 & 89 & 108 & 99 & 94 & 89 \\
\hline \hline
\end{tabular}

Note: Regressions are based on data for all CNEF countries listed in Table 5. Standard errors are heteroscedasticity-robust and indicated in brackets. ${ }^{* * *}=$ significant at the 1 percent level, $*_{*}=$ significant at the 5 percent level, $*=$ significant at the 10 percent level. Pre-government Gini and the share of the elderly (population above age 60 ) are own calculations from CNEF data. Exports in \% of GDP are from Penn World Tables 9.0. Migration per capita is from OECD.Stat. The role of luck is not included because only a maximum of three observations per country are available. 
Welfare state types and long-run redistribution. Finally, we test whether different welfare state types reveal a clear association with long-run redistribution. One might hypothesize that corporatist or Bismarckian welfare states are associated with lower redistribution ratios, given the relative importance of social insurance benefits. Therefore, in the Appendix, we repeat the regressions from Table 7, separately incorporating a dummy for Bismarckian and corporatist welfare states, while abandoning country fixed effects. Tables A.3 and A.4 in the Appendix show that the hypothesis is confirmed for some period and inequality specifications, while it is rejected for others. Similarly, interacting welfare state type and the share of the elderly does not show a clear relationship. Thus, we conclude that welfare state type does not suggest a specific association with long-run redistribution apart from what is captured by country fixed effects. On the one hand, this might indicate that welfare states are more country-specific and depend on more unique design features than what can be grasped using welfare state typologies. On the other hand, and probably more importantly, our cross-country analysis rests on only six different welfare states, for which we have long-run panel observations at the moment, whose number also differs across countries (hence, countries enter the regression analysis with different relative weights). Therefore, we conclude that properly investigating the specific role of welfare state types (based on general classifications) for long-run redistribution remains a question for future research, when more long-run panel data will hopefully be available for a wider range of welfare states in a harmonized way. 


\section{Conclusion}

An important feature of modern welfare states is that they do not just redistribute income between individuals but also smooth individual income over time. This paper investigates to what extent the measurement of redistribution in an annual framework, as widely used in the scientific literature and in policy debates, overstates actual redistribution between individuals in the long run in six different welfare states. Using panel data for Australia, Germany, South Korea, Switzerland, the United Kingdom, and the United States from the Cross-National Equivalent File (CNEF), we decompose total income inequality into income differences between individuals and individuals' income variation over time, and compute a redistribution ratio based on these inequality measures, capturing the long-run redistributive character of welfare states.

We find that the majority of income inequality is indeed explained by income differences between individuals. However, intra-individual inequality, i.e., individual income variation over time constitutes total inequality by a non-negligible percentage in all countries and rises when extending the measurement period. The share of reduction in interpersonal inequality decreases to nearly $80 \%$ for the maximum period length considered in Germany, Switzerland, the United Kingdom, and the United States.

Ranking countries by their relative redistributive impact in the long run (as opposed to insurance) shows that Anglo-American countries like the United Kingdom and the United States are - relative to overall redistribution - more redistributive between individuals over a longer perspective than the corporatist welfare state of Germany. The finding for Germany suggests support for the paradox of redistribution (Korpi and Palme; 1998), which states that redistributing resources in an annual context might be supported by the population if welfare states also offer high insurance.

We examine possible explanatory factors for cross-country differences in observed annual versus (relative) long-run redistribution. Regression results show that higher market income inequality is associated with more annual redistribution, whereas the impact is less clear and mostly negative for long-run redistribution. The latter finding suggests that higher market income inequality tends to be associated more with income smoothing than with long-run redistribution. Migration and trade openness are associated with lower long-run redistribution. The share of the elderly turns out to be a factor of particular interest, as a higher share of elderly in the population is associated with more annual, but less long-run redistribution between individuals. This can be explained by the growing share of elderly people, who might vote for systems that redistribute more on an annual basis by using social security contributions and taxes to fund public pensions. To reformulate the trade-off identified by Razin et al. (2002), we conclude that a greater number of retirees seem to have increased the demand for annual redistribution and insurance but decreased the demand for long-run redistribution. 


\section{References}

Alesina, A. and Angeletos, G.-M. (2005). Fairness and redistribution, American Economic Review 95(4): 960-980.

Alesina, A. and Giuliano, P. (2001). Preferences for redistribution, Handbook of Social Economics Volume 1A, Elsevier.

Baker, M. and Solon, G. (2003). Earnings dynamics and inequality among Canadian men, 1976-1992: Evidence from longitudinal income tax records, Journal of Labor Economics 21: 289-321.

Bartels, C. (2012). Redistribution and insurance in the German welfare state, Schmollers Jahrbuch - Journal of Applied Social Science Studies 132: 265-295.

Bartels, C. and Bönke, T. (2013). Can households and welfare states mitigate rising earnings instability?, Review of Income and Wealth 59(2): 250-282.

Beach, C. M., R. F. and Gray, D. (2010). Long-run inequality and short-run instability of men's and women's earnings in Canada, Review of Income and Wealth 56: 572596.

Benabou, R. and Ok, E. (2001). Social mobility and the demand for redistribution: the POUM hypothesis, Quarterly Journal of Economics 116(2): 447-487.

Bengtsson, N., Holmlund, B. and Waldenström, D. (2016). Lifetime versus annual taxand-transfer progressivity: Sweden, 1968-2009, Scandinavian Journal of Economics 188(4): 619-645.

Björklund, A. and Palme, M. (2002). Income redistribution within the life cycle versus between individuals: Empirical evidence using Swedish panel data, in T. P. D. Cohen and G. Saint-Paul (eds), The economics of rising inequality, Oxford University Press.

Blundell, R., Graber, M. and Mogstad, M. (2015). Labor income dynamics and the insurance from taxes, transfers, and the family, Journal of Public Economics 127: 5873 .

Bönke, T., Grabka, M., Schröder, C. and Wolff, E. (2020). A Head-to-Head Comparison of Augmented Wealth in Germany and the United States, Scandinavian Journal of Economics 112(3): 1140-1180.

Bonoli, G. (1997). Classifying welfare states: a two-dimension approach, Journal of Social Policy 26(3): 351-372. 
Bovenberg, A., Hansen, M. and Sorensen, P. (2008). Individual savings accounts for social insurance: Rationale and alternative designs, International Tax and Public Finance 15(1): 67-86.

Buchanan, J. (1976). Taxation in fiscal exchange, Journal of Public Economics 6(12): $17-29$.

Burkhauser, R., Butrica, B., Daly, M. and Lillard, D. (2001). The Cross-National Equivalent File: A product of cross-national research.

URL: http://sites.ehe.osu.edu/cnef/files/2012/11/P25-2.pdf

Cappellari, L. and Jenkins, S. (2014). Earnings and labour market volatility in britain, with a transatlantic comparison, Labour Economics 30: 201-211.

Casamatta, G., Cremer, H. and Pestieau, P. (2000). Political sustainability and the design of social insurance, Journal of Public Economics 75: 341-364.

Chen, W.-H. (2009). Cross-national difference in income mobility: Evidence from Canada, the United States, Great Britain and Germany, Review of Income and Wealth 55(1): 75-100.

Corneo, G. and Grüner, P. (2002). Individual preferences for political redistribution, Journal of Public Economics 83: 83-107.

Dahlberg, M., Edmark, K. and Lundqvist, H. (2012). Ethnic diversity and preferences for redistribution, Journal of Political Economy 120(1): 41-76.

DiNardo, J., Fortin, N. and Lemieux, T. (1996). Labor market institutions and the distribution of wages, 1973-1992: A semiparametric approach, Econometrica 64: 10011044 .

Dynan, K., D. E. and Sichel, D. (2012). The evolution of household income volatility, The B.E. Journal of Economic Analysis \& Policy 12(2): 1-40.

Dynarski, S. and Gruber, J. (1997). Can families smooth variable earnings?, Brookings Papers on Economic Activity pp. 229-303.

Esping-Andersen, G. (1990). The three worlds of welfare capitalism, Princeton University Press.

Fong, C. (2001). Social preferences, self-interest, and the demand for redistribution, Journal of Public Economics 82: 225-246.

Haan, P., Kemptner, D. and Prowse, V. (2018). Insurance, redistribution, and the inequality of lifetime income, IZA Discussion Paper No. 11275. 
Haider, S. (2001). Earnings instability and earnings inequality of males in the united states: 1967-1991, Journal of Labor Economics 19: 799-836.

Heathcote, J., Storesletten, K. and Violante, G. (2014). Consumption and labor supply with partial insurance: An analytical framework, American Economic Review 107(4): 2075-2126.

Hoynes, H. and Luttmer, E. (2011). The insurance value of state tax-transfer programs, Journal of Public Economics 95: 1466-1484.

Jensen, S., Lau, M. and Poutvaara, P. (2004). Efficiency and equity aspects of alternative social security rules, FinanzArchiv 60(3): 325-358.

Korpi, W. and Palme, J. (1998). The paradox of redistribution and strategies of equality: Welfare state institutions, inequality, and poverty in the western countries, American Sociological Review 63(5): 661-687.

Kwon, S. and Holliday, I. (2007). The Korean welfare state: a paradox of expansion in an era of globalisation and economic crisis, International Journal of Social Welfare 16: $242-248$.

Levell, P., Roantree, B. and Shaw, J. (2017). Mobility and the lifetime distributional impact of tax and transfer reforms, IFS Working Paper 17.7.

Luttmer, E. (2001). Group loyalty and the taste for redistribution, Journal of Political Economy 109(3): 6-34.

Meltzer, A. and Richard, S. (1981). A rational theory of the size of government, Journal of Political Economy 89(5): 914-927.

Milanovic, B. (2000). The median-voter hypothesis, income inequality, and income redistribution: an empirical test with the required data, European Journal of Political Economy 16: 367-410.

Moene, K. and Wallerstein, M. (2001). Inequality, social insurance, and redistribution, American Political Science Review 95(4): 859-874.

Moffitt, R. and Gottschalk, P. (2012). Trends in the transitory variance of male earnings - methods and evidence, Journal of Human Resources 47(1): 204-236.

Nelissen, J. (1995). Lifetime income redistribution by social security, Journal of Population Economics 8: 89-105.

Nelissen, J. (1998). Annual versus lifetime income redistribution by social security, Journal of Public Economics 68(2): 223-249. 
OECD (2017). Pensions at a Glance 201\%: OECD and G20 Indicators, OECD Publishing.

Pettersson, T. and Pettersson, T. (2007). Lifetime redistribution through taxes, transfers and non-cash benefits, in A. H. Tomas and A. Gupta (eds), Modelling our Future, Elsevier, pp. 205-232.

Ravallion, M. and Lokshin, M. (2000). Who wants to redistribute? the tunnel effect in 1990s Russia, Journal of Public Economics 76: 87-104.

Razin, E., Sadka, E. and Swagel, P. (2002). The aging population and the size of the welfare state, Journal of Political Economy 110(4): 900-918.

Reynolds, M. and Smolensky, E. (1977). Public Expenditures, Taxes, and the Distribution of Income: The United States, 1950, 1961, 1970, Academic Press.

Roantree, B. and Shaw, J. (2018). What a difference a day makes: inequality and the tax and benefit system from a long-run perspective, Journal of Economic Inequality 16: $23-40$.

Rodrik, D. (1998). Why do more open economies have bigger governments?, Journal of Political Economy 105(5): 997-1032.

Sandmo, A. (2002). Globalisation and the welfare state: More inequality - less redistribution?, Norwegian School of Economics and Business Administration Discussion Paper 4 .

Scervini, F. (2012). Empirics of the median voter: democracy, redistribution and the role of the middle class, Journal of Economic Inequality 10: 529-550.

Shin, D. and Solon, G. (2011). Trends in men's earnings volatility: What does the panel study of income dynamics show?, Journal of Public Economics 95: 973-982.

Shorrocks, A. (1978). Income inequality and income mobility, Journal of Economic Theory 19: 376-393.

Soroka, S., Banting, K. and Johnston, R. (2006). Immigration and redistribution in a global era, in P. Bardhan, S. Bowles and M. Wallerstein (eds), Globalization and Egalitarian Redistribution, Princeton University Press, pp. 261-288.

Tabellini, G. (2000). A positive theory of social security, Scandinavian Journal of Economics 102(3): 523-545.

Ter Rele, H. (2007). Measuring the lifetime redistribution achieved by Dutch taxation, cash transfer and non-cash benefits programs, Review of Income and Wealth 53(2): 335-362. 
Verbist, G. and Matsaganis, M. (2014). The redistributive capacity of services in the EU, in B. Cantillon and F. Vandenbroucke (eds), Reconciling Work and Poverty Reduction: How Successful Are European Welfare States?, Oxford University Press.

Zang, S. (2014). Wage shocks, household labor supply, and income instability, Journal of Population Economics 27(3): 767-796. 


\section{Appendix}

Figure A.1: Theil, redistribution ratio by period length and starting year
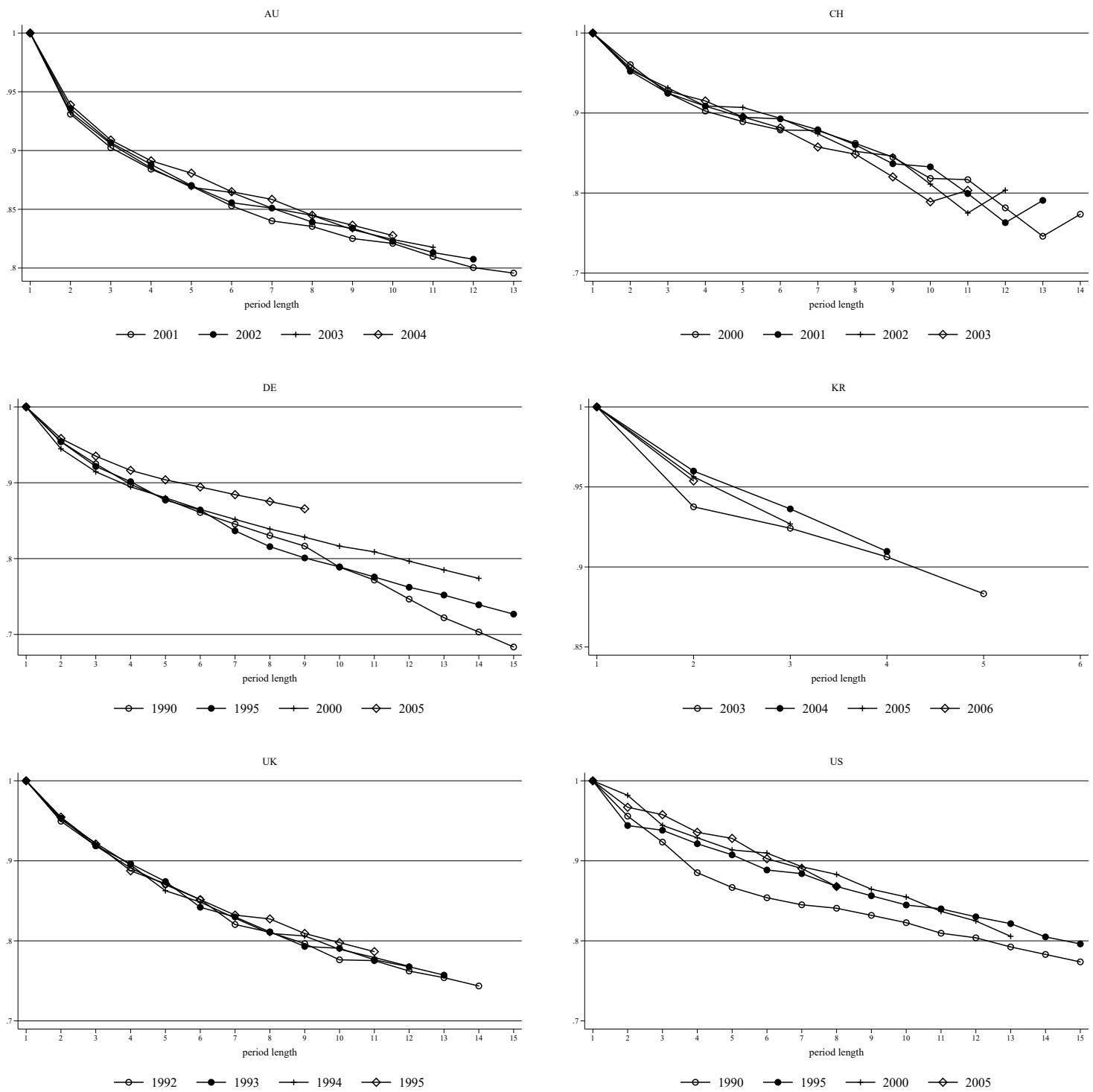

Source: Cross-National Equivalent File (CNEF). Note: Inequality is measured by the Theil coefficient. The redistribution ratio $R R$ is defined as $\left[I^{\text {between }}(Y)-I^{\text {between }}(X)\right] /[I(Y)-I(X)]$, where $Y$ is equivalized pre-government household income and $X$ is equivalized post-government household income in 2010 USD PPP. Each country plot displays ratios by period length for four selected starting years. We use at least some starting years around the millennium for all countries except the United Kingdom, where panel data including post-government incomes are only available until 2006, such that the earliest starting year for a 14-year period length is 1992. 
Figure A.2: MLD decomposition by period length, for different starting years
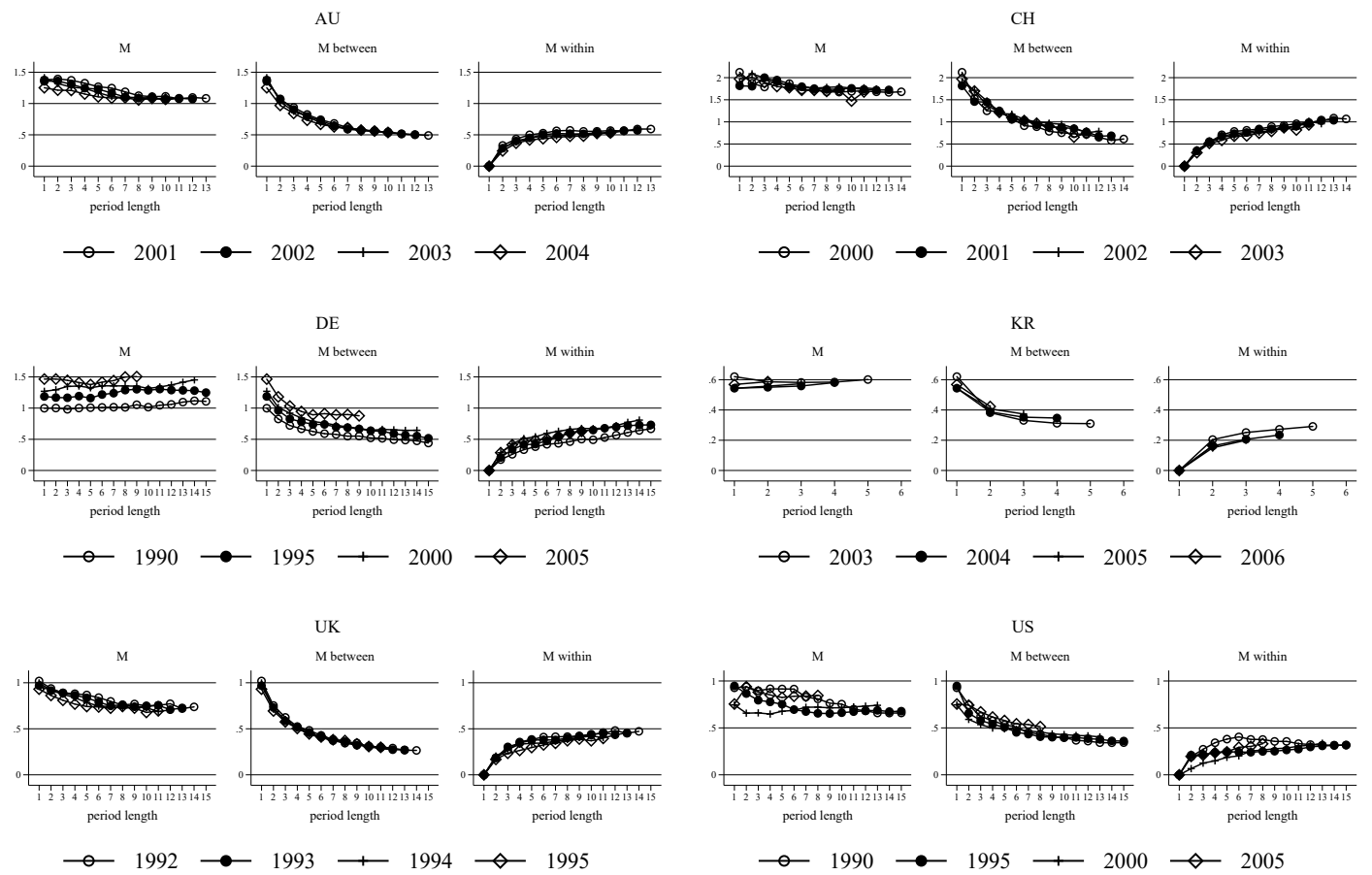

Source: Own calculations, Cross-National Equivalent File (CNEF). Note: MLD indices are calculated based on pregovernment equivalized household income in 2010 USD PPP for a maximum period length of 15 years. We use at least some starting years around the millennium for all countries except the United Kingdom, where panel data including post-government incomes are only available until 2006, such that the earliest starting year for a 14-year period length is 1992 .

Figure A.3: MLD, government reduction of the between and within component by period length
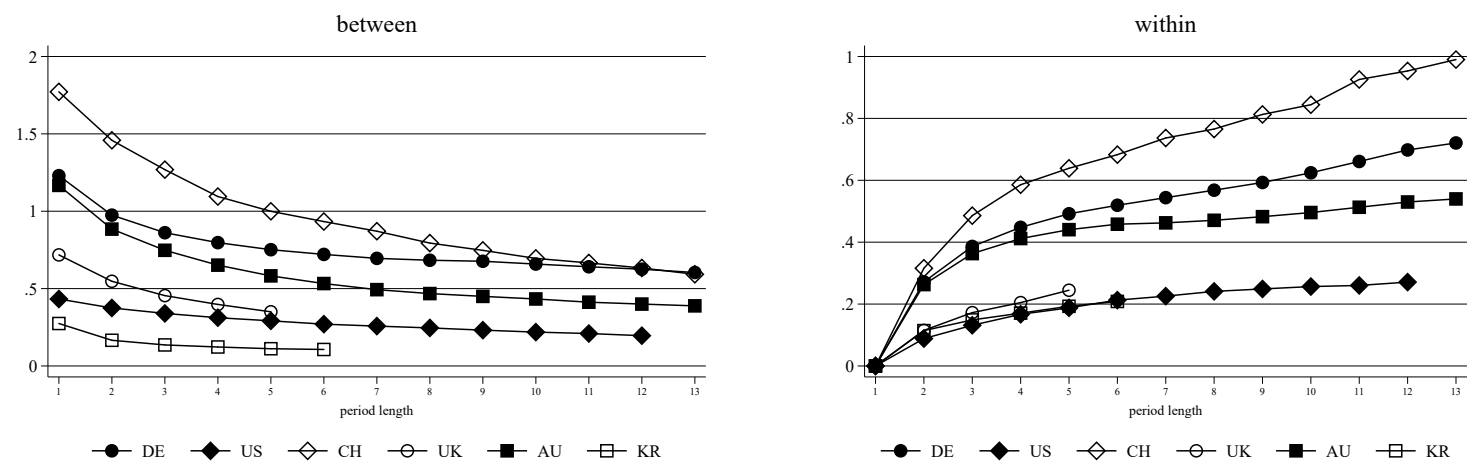

Source: Own calculations, Cross-National Equivalent File (CNEF). Note: Inequality is measured by the MLD coefficient. Inequality reduction is measured by the redistribution index $R=I(Y)-I(X)$, where $Y$ is equivalized pre-government household income and $X$ is equivalized post-government household income in 2010 USD PPP. Average values over starting years 2001 to 2005 . 
Figure A.4: MLD, redistribution ratio by period length and starting year
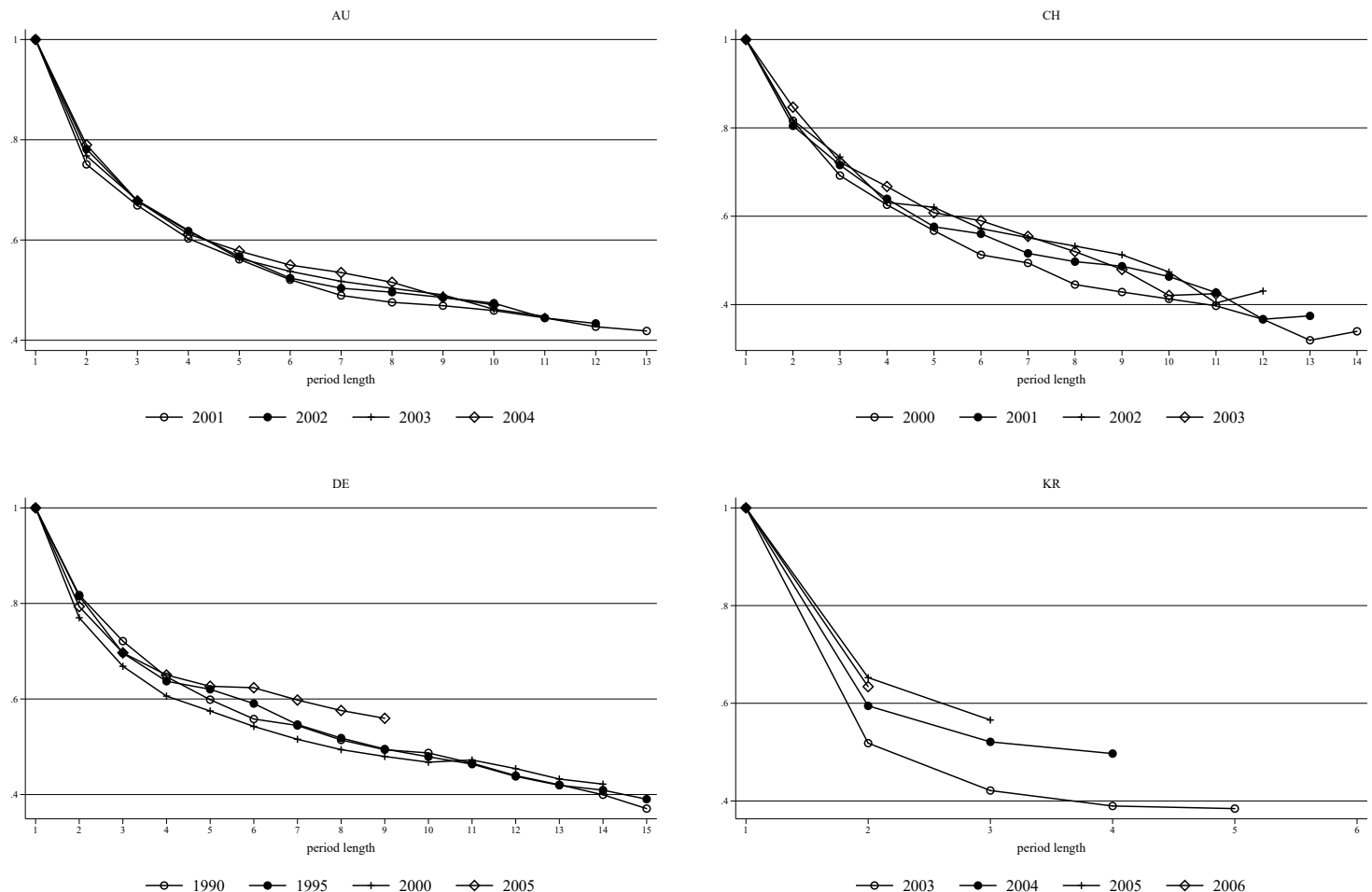

UK
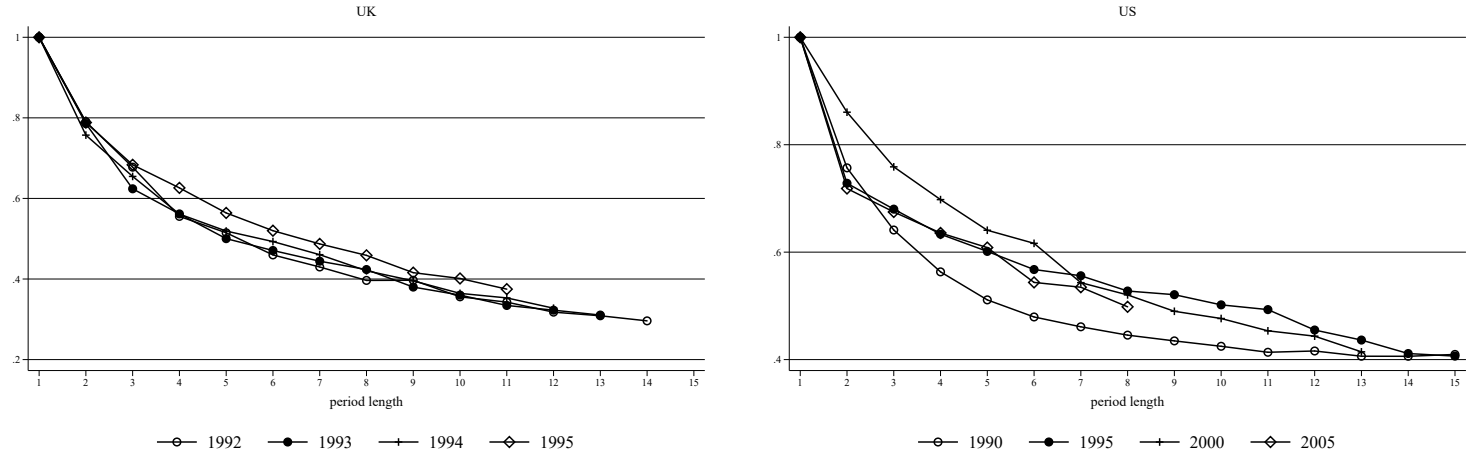

Source: Cross-National Equivalent File (CNEF). Note: Inequality is measured by the MLD coefficient. The redistribution ratio $R$ is $\left[I^{\text {between }}(Y)-I^{\text {between }}(X)\right] /[I(Y)-I(X)]$, where $Y$ is equivalized pre-government household income and $X$ is equivalized post-government household income in 2010 USD PPP. Each country plot displays ratios by period length for four selected starting years. We use at least some starting years around the millennium for all countries except the United Kingdom, where panel data including post-government incomes are only available until 2006, such that the earliest starting year for a 14-year period length is 1992. 
Table A.1: Explaining annual redistribution

\begin{tabular}{lccccc}
\hline \hline \multicolumn{5}{c}{ Dependent variable: annual redistribution $R_{1}$ based on MLD } \\
& $(1)$ & $(2)$ & $(3)$ & $(4)$ & $(5)$ \\
\hline Pre-gov.gini & $2.263^{* *}$ & $4.748^{* * *}$ & $2.609^{* *}$ & $2.705^{*}$ & -2.427 \\
& $(0.905)$ & $(1.288)$ & $(1.114)$ & $(1.532)$ & $(2.263)$ \\
Elderly share & & & $3.483^{* * *}$ & $2.757^{* * *}$ & $6.225^{* * *}$ \\
& & & $(0.609)$ & $(0.720)$ & $(1.092)$ \\
Exports \% of GDP & & & & $0.631^{*}$ & -0.970 \\
& & & & $(0.338)$ & $(0.784)$ \\
Migrants p.c. & & & & -4.679 & -4.261 \\
& & & & $(10.296)$ & $(10.399)$ \\
Luck & & & & & -0.140 \\
& No & Yes & Yes & Yes & Yes \\
Country/year effects & 0.032 & 0.906 & 0.936 & 0.939 & 0.967 \\
Adj. $R^{2}$ & 119 & 119 & 119 & 114 & 45 \\
N & & & & & \\
\hline \hline
\end{tabular}

Note: Regressions are based on data for all CNEF countries listed in Table 5. Standard errors are heteroscedasticity-robust and indicated in brackets. $* * *=$ significant at the 1 percent level, $* *=$ significant at the 5 percent level, ${ }^{*}=$ significant at the 10 percent level. Pre-government Gini and the share of the elderly (population above age 60) are own calculations from CNEF data. Exports in \% of GDP are from Penn World Tables 9.0. Migration per capita is from OECD.Stat. The role of luck is from the World Value Survey 1994, 2005, 2010. Fewer observations in (4) and (5) are due to fewer country-year observations for the respective explanatory variables. 
Table A.2: Explaining long-run redistribution, working-age population

\begin{tabular}{lcccccccc}
\hline \hline & \multicolumn{8}{c}{ Dependent variable: redistribution ratio $R R_{p}$ based on } \\
& \multicolumn{9}{c}{ Theil } & \multicolumn{7}{c}{ MLD } \\
& $R R_{2}$ & $R R_{3}$ & $R R_{4}$ & $R R_{5}$ & $R R_{2}$ & $R R_{3}$ & $R R_{4}$ & $R R_{5}$ \\
\hline Pre-gov.gini & $-0.155^{* * *}$ & 0.129 & $-0.152^{* *}$ & $0.301^{* * *}$ & $-0.661^{* *}$ & $-0.366^{* *}$ & $-0.706^{* * *}$ & $0.240^{* * *}$ \\
& $(0.055)$ & $(0.108)$ & $(0.070)$ & $(0.110)$ & $(0.308)$ & $(0.166)$ & $(0.204)$ & $(0.073)$ \\
Elderly share & $-0.122^{* * *}$ & $-0.263^{* * *}$ & $-0.193^{* * *}$ & $-0.191^{* * *}$ & $-0.626^{* * *}$ & $-0.711^{* * *}$ & -0.097 & $-0.629^{* * *}$ \\
& $(0.018)$ & $(0.049)$ & $(0.060)$ & $(0.049)$ & $(0.107)$ & $(0.126)$ & $(0.240)$ & $(0.106)$ \\
Exports \% of GDP & $0.045^{* *}$ & $0.127^{* * *}$ & $0.157^{* * *}$ & $0.094^{* * *}$ & 0.052 & $0.089^{* * *}$ & -0.015 & $0.092^{* * *}$ \\
& $(0.018)$ & $(0.017)$ & $(0.026)$ & $(0.035)$ & $(0.039)$ & $(0.032)$ & $(0.071)$ & $(0.031)$ \\
Migrants p.c. & -1.171 & -0.942 & -0.297 & -0.585 & -2.394 & -1.664 & -0.173 & 0.583 \\
& $(1.202)$ & $(0.592)$ & $(0.353)$ & $(0.552)$ & $(2.405)$ & $(1.468)$ & $(0.765)$ & $(0.866)$ \\
\hline Country/year effects & Yes & Yes & Yes & Yes & Yes & Yes & Yes & Yes \\
$\mathrm{N}$ & 108 & 99 & 94 & 89 & 108 & 99 & 94 & 89 \\
\hline \hline
\end{tabular}

Note: Regressions are based on data for all CNEF countries listed in Table 5, including the working-age population only (aged 25-55). Standard errors are heteroscedasticity-robust and indicated in brackets. ${ }^{* * *}=$ significant at the 1 percent level, ${ }^{* *}=$ significant at the 5 percent level, $*=$ significant at the 10 percent level. Pre-government Gini and the share of the elderly (population above age 60) are own calculations from CNEF data. Exports in \% of GDP are from Penn World Tables 9.0. Migration per capita is from OECD.Stat. The role of luck is not included because only a maximum of three observations per country are available. 
Table A.3: Explaining long-run redistribution, welfare state type I

\begin{tabular}{lcccccccc}
\hline \hline & \multicolumn{8}{c}{ Dependent variable: redistribution ratio $R R_{p}$ based on } \\
& $R R_{2}$ & $R R_{3}$ & $R R_{4}$ & $R R_{5}$ & $R R_{2}$ & $R R_{3}$ & $R R_{4}$ & $R R_{5}$ \\
\hline Pre-gov.gini & $-0.102^{*}$ & $0.175^{* *}$ & -0.084 & -0.084 & $-0.760^{* *}$ & $-0.213^{* *}$ & -0.010 & $0.616^{* * *}$ \\
& $(0.059)$ & $(0.082)$ & $(0.055)$ & $(0.078)$ & $(0.342)$ & $(0.096)$ & $(0.102)$ & $(0.110)$ \\
Elderly share & 0.010 & -0.037 & $0.045^{* *}$ & -0.011 & -0.180 & -0.155 & $0.125^{*}$ & -0.040 \\
& $(0.048)$ & $(0.088)$ & $(0.022)$ & $(0.043)$ & $(0.116)$ & $(0.138)$ & $(0.072)$ & $(0.056)$ \\
Corporatist x Elderly share & 0.057 & 0.016 & 0.055 & $0.346^{* * *}$ & $1.168^{* * *}$ & $-0.377^{* * *}$ & $-0.537^{* * *}$ & $-0.765^{* * *}$ \\
& $(0.058)$ & $(0.082)$ & $(0.072)$ & $(0.062)$ & $(0.401)$ & $(0.070)$ & $(0.131)$ & $(0.090)$ \\
Corporatist & -0.018 & -0.012 & -0.017 & $-0.132^{* * *}$ & $-0.449^{* * *}$ & $0.178^{* * *}$ & $0.228^{* * *}$ & $0.300^{* * *}$ \\
& $(0.021)$ & $(0.026)$ & $(0.030)$ & $(0.024)$ & $(0.144)$ & $(0.032)$ & $(0.054)$ & $(0.033)$ \\
Exports \% of GDP & -0.030 & -0.003 & $-0.083^{* *}$ & $-0.046^{* *}$ & 0.013 & $0.087^{* * *}$ & 0.024 & $0.090^{* * *}$ \\
& $(0.027)$ & $(0.017)$ & $(0.033)$ & $(0.018)$ & $(0.068)$ & $(0.014)$ & $(0.042)$ & $(0.021)$ \\
Migrants p.c. & -0.169 & -0.307 & $0.883^{* *}$ & 0.104 & -1.451 & $-3.985^{* * *}$ & -0.930 & $-2.721^{* * *}$ \\
& $(0.374)$ & $(0.367)$ & $(0.388)$ & $(0.414)$ & $(2.848)$ & $(1.515)$ & $(0.985)$ & $(0.411)$ \\
\hline Year effects & Yes & Yes & Yes & Yes & Yes & Yes & Yes & Yes \\
N & 108 & 99 & 94 & 89 & 108 & 99 & 94 & 89 \\
\hline \hline
\end{tabular}

Note: Regressions are based on data for all CNEF countries listed in Table 5, with Germany and South Korea grouped as corporatist welfare states. Standard errors are

heteroscedasticity-robust and indicated in brackets. ${ }^{* * *}=$ significant at the 1 percent level, ${ }^{* *}=$ significant at the 5 percent level, ${ }^{*}=$ significant at the 10 percent level. Pre-government Gini and the share of the elderly (population above age 60) are own calculations from CNEF data. Exports in \% of GDP are from Penn World Tables 9.0. Migration per capita is from OECD.Stat. The role of luck is not included because only a maximum of three observations per country are available. 
Table A.4: Explaining long-run redistribution, welfare state type II

\begin{tabular}{lcccccccc}
\hline \hline & \multicolumn{8}{c}{ Dependent variable: redistribution ratio $R R_{p}$ based on } \\
& $R R_{2}$ & $R R_{3}$ & $R R_{4}$ & $R R_{5}$ & $R R_{2}$ & $R R_{3}$ & $R R_{4}$ & $R R_{5}$ \\
\hline Pre-gov.gini & $-0.105^{*}$ & $0.152^{*}$ & $-0.089^{*}$ & 0.001 & $-0.752^{* *}$ & -0.162 & 0.080 & $0.725^{* * *}$ \\
& $(0.060)$ & $(0.086)$ & $(0.047)$ & $(0.091)$ & $(0.352)$ & $(0.212)$ & $(0.192)$ & $(0.178)$ \\
Elderly share & 0.027 & -0.045 & $0.040^{* *}$ & -0.023 & $-0.157^{*}$ & -0.076 & $0.223^{* * *}$ & 0.098 \\
& $(0.052)$ & $(0.095)$ & $(0.019)$ & $(0.038)$ & $(0.086)$ & $(0.144)$ & $(0.075)$ & $(0.067)$ \\
Bismarck x Elderly share & 0.032 & -0.001 & 0.059 & 0.141 & $0.992^{* *}$ & -0.186 & $-0.350^{* *}$ & $-0.704^{* * *}$ \\
& $(0.071)$ & $(0.081)$ & $(0.044)$ & $(0.137)$ & $(0.428)$ & $(0.126)$ & $(0.173)$ & $(0.177)$ \\
Bismarck & -0.001 & -0.001 & -0.015 & -0.055 & $-0.387^{* *}$ & $0.108^{* * *}$ & $0.167^{* * *}$ & $0.289^{* * *}$ \\
& $(0.028)$ & $(0.025)$ & $(0.022)$ & $(0.051)$ & $(0.162)$ & $(0.038)$ & $(0.054)$ & $(0.053)$ \\
Exports \% of GDP & -0.046 & -0.005 & $-0.095^{* *}$ & -0.012 & 0.080 & 0.007 & $-0.103^{*}$ & -0.021 \\
& $(0.030)$ & $(0.022)$ & $(0.041)$ & $(0.029)$ & $(0.192)$ & $(0.043)$ & $(0.062)$ & $(0.047)$ \\
Migrants p.c. & -0.342 & -0.316 & $0.869^{*}$ & -0.424 & -0.958 & $-4.302^{* *}$ & -0.418 & $-3.279^{* * *}$ \\
& $(0.466)$ & $(0.353)$ & $(0.456)$ & $(0.622)$ & $(3.854)$ & $(1.877)$ & $(0.971)$ & $(0.631)$ \\
\hline Year effects & Yes & Yes & Yes & Yes & Yes & Yes & Yes & Yes \\
$\mathrm{N}$ & 108 & 99 & 94 & 89 & 108 & 99 & 94 & 89 \\
\hline \hline
\end{tabular}

Note: Regressions are based on data for all CNEF countries listed in Table 5, with Germany, Switzerland, and South Korea grouped as Bismarckian welfare states. Standard errors are heteroscedasticity-robust and indicated in brackets. ${ }^{* * *}=$ significant at the 1 percent level, ${ }^{* *}=$ significant at the 5 percent level, ${ }^{*}=$ significant at the 10 percent level. Pre-government Gini and the share of the elderly (population above age 60) are own calculations from CNEF data. Exports in \% of GDP are from Penn World Tables 9.0. Migration per capita is from OECD.Stat. The role of luck is not included because only a maximum of three observations per country are available. 